\title{
Statistical-Dynamical Downscaling Projections of Tropical Cyclone Activity in a Warming Climate: Two Diverging Genesis Scenarios
}

\author{
Chia-Ying LeE And SuZana J. CAMARgo \\ Lamont-Doherty Earth Observatory, Columbia University, Palisades, New York \\ ADAM H. SOBEL \\ Department of Applied Physics and Applied Mathematics, Columbia University, New York, and \\ Lamont-Doherty Earth Observatory, Columbia University, Palisades, New York \\ MiCHAEL K. TIPPETT \\ Department of Applied Physics and Applied Mathematics, Columbia University, New York, New York
}

(Manuscript received 19 June 2019, in final form 11 February 2020)

\begin{abstract}
Tropical cyclone (TC) activity is examined using the Columbia Hazard model (CHAZ), a statistical-dynamical downscaling system, with environmental conditions taken from simulations from phase 5 of the Coupled Model Intercomparison Project (CMIP5) for both the historical period and a future scenario under the representative concentration pathway 8.5. Projections of individual global and basin TC frequency depend sensitively on the choice of moisture variable used in the tropical genesis cyclone index (TCGI) component of CHAZ. Simulations using column relative humidity show an increasing trend in the future, while those using saturation deficit show a decreasing trend, although both give similar results in the historical period. While the projected annual TC frequency is also sensitive to the choice of model used to provide the environmental conditions, the choice of humidity variable in the TCGI is more important. Changes in TC frequency directly affect the projected TCs' tracks and the frequencies of strong storms on both basin and regional scales. This leads to large uncertainty in assessing regional and local storm hazards. The uncertainty here is fundamental and epistemic in nature. Increases in the fraction of major TCs, rapid intensification rate, and decreases in forward speed are insensitive to TC frequency, however. The present results are also consistent with prior studies in indicating that those TC events that do occur will, on average, be more destructive in the future because of the robustly projected increases in intensity.
\end{abstract}

\section{Introduction}

As Earth's climate warms due to increasing concentrations of greenhouse gases, tropical cyclones (TCs) are expected to change. Among the more confident expectations are that TC precipitation and wind speeds will increase, and that the impact of storm surge will increase due to rising sea levels (Knutson et al. 2010; Woodruff et al. 2013; Walsh et al. 2016; Camargo and Wing 2016; Sobel et al. 2016). There is much less confidence in projections of changes in TC frequency, or in the spatial distributions of storm genesis, track patterns, and

๑ Denotes content that is immediately available upon publication as open access.

Corresponding author: Chia-Ying Lee, cl3225@columbia.edu translation speeds. The uncertainties are, in general, even larger at the scale of individual basins than at the global scale, and larger still at subbasin scales. Yet changes in frequency and track patterns influence all other aspects of the hazard at any specific location, making hazard assessment challenging. Here we study projections of various measures of TC climatology on both global and basinwide scales under warming climates. We use environmental conditions derived from coupled global Earth system models, downscaled using a statistical-dynamical tropical cyclone hazard model.

Projections of tropical cyclone frequency are of particular interest. With low confidence, many recent studies have suggested a decline in the global number of TCs with warming (e.g., IPCC 2013; Knutson et al. 2010), with a few exceptions (e.g., Emanuel 2013; Bhatia et al. 2018; Fedorov et al. 2018). One hypothesized mechanism for 
the reduction is the decrease of mean ascending midtropospheric vertical velocity in genesis regions due to increasing static stability (Held and Zhao 2011; Sugi and Yoshimura 2012; Sugi et al. 2012). Another is an increase in the saturation deficit, which increases the time scale for the free troposphere in a TC to reach saturation through surface evaporation (Emanuel 2008; Rappin et al. 2010). On the other hand, possible mechanisms for increasing annual TC frequency include increases in potential intensity (PI), and in particular, increases in the area over which the PI is sufficiently large to sustain genesis, due to the reduction in the meridional temperature gradient and relative warming at the poleward boundaries of the historical zones of TC activity (Fedorov et al. 2018; Viale and Merlis 2017). In a recent study using the $25-\mathrm{km}$ High-Resolution ForecastOriented Low Ocean Resolution (HiFLOR) model at the Geophysical Fluid Dynamics Laboratory (GFDL), Bhatia et al. (2018) showed an increasing trend in TC frequency as the climate warms. This increase is in agreement with the downscaling results of Emanuel (2013) for phase 5 of the Coupled Model Intercomparison (CMIP5), but in disagreement with many previous studies, as reviewed, for example, in Walsh et al. (2016). Unlike the case of TC intensity, where PI theory complements numerical experiments, there is no established theory for TC genesis to help us interpret the conflicting results from different modeling studies.

For regional hazards, changes in the spatial patterns of TC genesis and track are potentially as important as changes in basinwide frequency, if not more so. Any changes in the sizes or positions of the main genesis locations are likely to affect the distributions of storm tracks (Wang and Chan 2002; Camargo et al. 2007; Daloz et al. 2015). Changes in large-scale steering flows may also change the preferred direction and speed of TCs' forward motion (Colbert et al. 2013). Murakami and Wang (2010) found a decrease in the TC occurrence in the tropical western North Atlantic, but an increase in the tropical eastern North Atlantic, notwithstanding an overall reduction in the North Atlantic genesis. Yokoi et al. (2013) showed that the increases in the frequency of eastern Japan storms are due to changes in the storms' translation direction, which resulted from the southward shift of the subtropical jet axis and resultant intensification of westerly steering flows. With a set of global climate models (GCMs), Nakamura et al. (2017) further identified an eastward and a poleward shift in the typhoon tracks as the climate warms. Using observed tracks from 1945 to 2015, Kossin (2018) found a slowdown of TCs' mean translation speed. Such a slowdown has not yet been shown to be a feature of future projections, but it is arguably consistent with the projection of a slowing down of the atmospheric circulation (Held and Soden 2006; Vecchi et al. 2006), which is in turn due to a more stable tropical atmosphere (Ma et al.2012; He and Soden 2015).

In contrast to genesis and track, it is broadly agreed that greenhouse gas-driven warming will result in stronger storm intensities. This expectation is supported by PI theory as well as numerical model simulations. The emergence of the signal thus far is likely muted by aerosol cooling, whose impact on PI is comparable, but of opposite sign, to the greenhouse gas-driven increase (Ting et al. 2015; Sobel et al. 2016). The greenhouse warming is expected to increasingly outpace aerosol cooling in future (Westervelt et al. 2015). The fraction of TCs that become intense (exceeding category 3 or 4 on the Saffir-Simpson scale, depending on the study) is projected to increase under continued warming; Knutson et al. (2015), Sugi et al. (2017), and Yoshida et al. (2017), for example, showed that fraction of intense TCs will increase, even though overall TC frequency will decrease. On the other hand, Bhatia et al. (2018) projected that both the fraction of intense TCs and overall TC frequency will increase. Because TCs rarely reach major hurricane strength without undergoing rapid intensification [RI; i.e., intensity increases of more than $35 \mathrm{kt}(24 \mathrm{~h})^{-1}\left(1 \mathrm{kt} \approx 0.51 \mathrm{~m} \mathrm{~s}^{-1}\right)$ ] (Lee et al. 2016b), the increasing numbers of strong storms is likely to mean increasing numbers of storms undergoing RI as well (Kowch and Emanuel 2015; Emanuel 2017). Using 24-hourly storm data from both observations and the high-resolution GCM simulations, Bhatia et al. (2019) further found a significant increase in the frequency of RI events in the past 30 years of historical observations and in future climate projections.

We are interested in how global climate change will influence TC hazards regionally. To do this, we use a statistical-dynamical downscaling approach in which we downscale six CMIP5 models using the Columbia Hazard model (CHAZ), developed in previous work (Lee et al. 2018). The CHAZ model, the CMIP5 model simulations, and the downscaling experiments themselves are described in section 2. Differences in the large-scale conditions in CMIP5 models between current and projected future climates are shown in section 3 . We discuss changes in the statistics of synthetic storms' genesis, tracks, and intensities on global and basinwide scales in sections 4 and 5. In section 6 we show the estimated TC hazards from CHAZ simulations, followed by conclusions in section 7 .

\section{Methods and experiment design}

\section{a. The Columbia Hazard model}

The Columbia Hazard model (CHAZ) has been developed and tested using data from the recent historical 
climate. The model is composed of three separate components, which predict genesis, track, and intensity, respectively. The method is described in detail in Lee et al. (2018), but we give a brief summary here.

The genesis model seeds the domain with weak vortices (or disturbances) using a seeding rate that depends on environmental conditions through a tropical cyclone genesis index (TCGI). The index is described by Tippett et al. (2011) and Camargo et al. (2014). The weak seed vortices are then passed to the intensity and track models to determine the storms' further evolution. The track model moves each storm forward by advection by the environmental wind plus a "beta drift" component. The advection is calculated using steering flow, defined as

$$
\mathbf{V}_{\text {steering_flow }}=0.8 \mathbf{V}_{850}+0.2 \mathbf{V}_{250}
$$

where $\mathbf{V}$ are monthly mean wind at 850 and $200 \mathrm{hPa}$, plus a stochastic component based on eddy statistics that represents the effects of submonthly wind fluctuations (Emanuel et al. 2006).

The intensity model (Lee et al. 2015, 2016a) has two components. The first is an empirical multiple linear regression model, which advances the TC intensity in time along the track based on the surrounding large-scale environment and is similar in construction to statistical models used in operational forecasting (DeMaria et al. 2005). The second is a stochastic component that accounts for the internal storm dynamics and does not depend explicitly on the environment, but only on the storm's current state and recent history. Intensity at landfall is calculated from a separate regression model that takes into account the proximity to land, as well other environmental conditions.

Ambient environmental variables required by the CHAZ model are potential intensity (PI; Bister and Emanuel 2002), deep-layer (850-250 hPa) vertical wind shear (SHR), moisture variables [relative humidity and/ or saturation deficit (SD)], the absolute vorticity at $850 \mathrm{hPa}\left(\eta_{850}\right)$, and the steering flow [Eq. (1)]. We use monthly data interpolated to daily resolution. The only exception is the eddy statistics used in the track model, which are calculated using daily winds. Humidity enters in multiple ways: the intensity model uses area-averaged midlevel humidity (Lee et al. 2015) while TCGI uses grid values of either column-integral relative humidity (CRH; Tippett et al. 2011) or SD (Camargo et al. 2014). SD is the difference between the column integrated water vapor and the same quantity at saturation, and the $\mathrm{CRH}$ is their ratio. Both are calculated following Bretherton et al. (2004). The choice between these two humidity variables in TCGI will prove consequential in this study.

\section{b. Downscaling experiments and CMIP5 models}

In this study, synthetic storms are generated by downscaling six models from phase 5 of the Coupled Model Intercomparison Project (CMIP5; Taylor et al. 2012). They are the National Center for Atmospheric Research (NCAR) Community Climate System Model 4 (CCSM4; Gent et al. 2011); the Geophysical Fluid Dynamics Laboratory Climate Model, version 3, from (GFDL CM3; Donner et al. 2011); the UK Met Office Hadley Center Global Environment Model, version 2, Earth System (HadGEM2-ES; Jones et al. 2011), the Max Planck Institution Earth System Model with medium resolution (MPI-ESM-MR; Zanchettin et al. 2012); the Model for Interdisciplinary Research on Climate, version 5 (MIROC5; Watanabe et al. 2010), from the University of Tokyo Center for Climate System Research, the National Institute for Environmental Studies, and Japan Agency for Marine-Earth Science and Technology Frontier Research Center for Global Change; and the Meteorological Research Institute of Japan's Climate General Circulation Model 3 (MRICGCM3; Yukimoto et al. 2012). Those models were selected following Emanuel (2013), allowing direct comparison with that study. While more models are available from CMIP5, it turns out that the greatest uncertainty in our results derives not from the model being downscaled but from the choice of moisture variable used in TCGI, as described below. Thus, six models are more than adequate to illustrate the most challenging issue that arises in this study.

Applying the TCGI to a set of simulations of the GFDL High-Resolution Atmospheric Model (HiRAM; Zhao et al. 2009) at 50-km horizontal grid spacing, Camargo et al. (2014) found that using saturation deficit (SD) as the moisture variable in the TCGI results in a reduced frequency of TCs globally in a warming climate, while using $\mathrm{CRH}$ results in an increase. The results from the SD choice were consistent with the directly simulated storm genesis reduction from HiRAM, while those from the CRH choice were not. Based on this, as well as on a simple theoretical argument, it was suggested that $\mathrm{SD}$ is a better choice for the moisture variable of TCGI for climate change studies. These results, however, were contingent on the HiRAM simulations; Camargo et al. (2014) was a "perfect model" study, taking that modelwhich at the time agreed qualitatively with most other global models at comparable resolutions-as the target to be explained. As discussed in the introduction (section 1), however, there is now a larger uncertainty in the future projection of TC frequency, as simulations 
from a global model with $25-\mathrm{km}$ horizontal grid spacing show an increasing trend (Bhatia et al. 2018), as do the downscaling simulations of Emanuel (2013). Many other models still project decreases, however, and given the absence of physical theory for TC frequency, this leads us to be uncertain about the sign, let alone the magnitude of expected future changes.

Considering the complex set of results from the prior studies cited above, here we design two sets of simulations. In the first, $\mathrm{CRH}$ is used as the moisture variable:

$\mu=\exp \left(b+b_{\eta} \eta_{850, c}+b_{\mathrm{CRH}} \mathrm{CRH}+b_{\mathrm{PI}} \mathrm{PI}+b_{\mathrm{SHR}} \mathrm{SHR}\right)$,

while SD is used in the second:

$$
\mu=\exp \left(b+b_{\eta} \eta_{850, c}+b_{\mathrm{SD}} \mathrm{SD}+b_{\mathrm{PI}} \mathrm{PI}+b_{\mathrm{SHR}} \mathrm{SHR}\right) .
$$

Here $\mu$ is the estimated seeding rate and $b$ is the intercept; $b_{X}$ represents the coefficient of parameter $X$. The subscript $c$ in $\eta_{850, c}$ indicates that TCGI uses absolute vorticity clipped at $3.7 \times 10^{-5} \mathrm{~s}^{-1}$ (Tippett et al. 2011). We call these two sets of experiments TCGI_CRH and TCGI_SD.

The two versions of TCGI and six CMIP5 models give a total of 12 experiments. In each experiment, we generate 120 simulations of each year from 1981 to 2100 . The CHAZ track set records 6-hourly storm location (in longitude and latitude) and maximum wind speed (kt). Large-scale environmental conditions for the period of 1981-2005 are taken from the historical simulations, and those for the periods from 2006 to 2100 are from future climate simulations under representative concentration pathway 8.5 (RCP8.5) scenarios. To understand the modulation of TC activity by climate change, we analyze trends from 1981 to 2100 as well as differences in the climatologies of the periods: 19812005, 2006-40, 2041-70, and 2071-2100. The last period (2071-2100) is referred to as the late twenty-first century. For convenience, we refer to simulations of the historical period as HIST and those for the late twenty-first century as RCP85 hereafter.

\section{c. TC basins and observations}

We analyze TC climatology both globally and basinwide. Following the conventional definitions, the seven TC basins are the north Indian Ocean (ni; west of $110^{\circ} \mathrm{E}$ ), western North Pacific (wnp; $110^{\circ}-180^{\circ} \mathrm{E}$ ), eastern North Pacific (enp), North Atlantic (atl), south Indian Ocean (sin; $0^{\circ}-90^{\circ} \mathrm{E}$ ), northern Australia (aus; $90^{\circ}-160^{\circ} \mathrm{E}$ ), and South Pacific (spc; $\left.160^{\circ} \mathrm{E}-120^{\circ} \mathrm{W}\right)$.
The TC season for the Southern Hemispheric basins crosses the calendar year, from December to May, and thus annual values (such as annual TC frequency) in these basins are usually calculated from July to June (Schreck et al. 2014). In this study, however, we calculate annual values using calendar year, January to December, for all basins. We are looking at TC climatologies over 20-30 years, rather than at interannual variability; thus it is not necessary to calculate annual values following the individual TC seasons. Furthermore, it is easier to attribute the impact of TC activity in individual basins to the global total when the annual values are defined over the same period.

Simulated TC climatologies from the historical periods are compared to the observations from the International Best Track Archive for Climate Stewardship v03r08 (IBTrACS; Knapp et al. 2010). IBTrACS contains data from various operational centers. Here we use those from the National Hurricane Center (NHC) and Joint Typhoon Warning Center (JTWC). We use the 6-hourly storm location (in longitude and latitude) and maximum wind speed (kt) from 1981 to 2013.

\section{d. Bias correction}

When downscaling CHAZ from the CMIP5 model data, the parameters in the equations for genesis, storm motion, and intensity change may need to be adjusted. The model was trained using observation-based reanalysis data, and the most appropriate statistical relationships between environmental parameters and TC genesis, track, and intensity might differ when using climate models' environmental fields, due to biases in the models' climates. However, CMIP5 climate models do not simulate realistically the observed TC frequency and (especially) intensity distributions, due to their low horizontal resolutions (Camargo 2013). So, adjusting CHAZ to capture their simulated TC climatologies would defeat the purpose of using a statistical-dynamical downscaling approach. While we are interested in the differences in the synthetic storm climatologies under RCP8.5 scenario relative to those from historical period, it is appropriate to calibrate the model results first. By comparing the annual TC frequency in HIST to the observations, we derive a multiplicative factor that will be used as a correction when applied to the TCGI. The correction factor is uniform in time but varies by basin. Then, the same correction is applied to all the simulations for warming climate. We derived correction factors for storm speed and landfall hazards during postprocessing. No bias correction is applied to the TC intensity, because CHAZ is capable of generating storm intensities realistically, including the bimodality in basin distributions of 

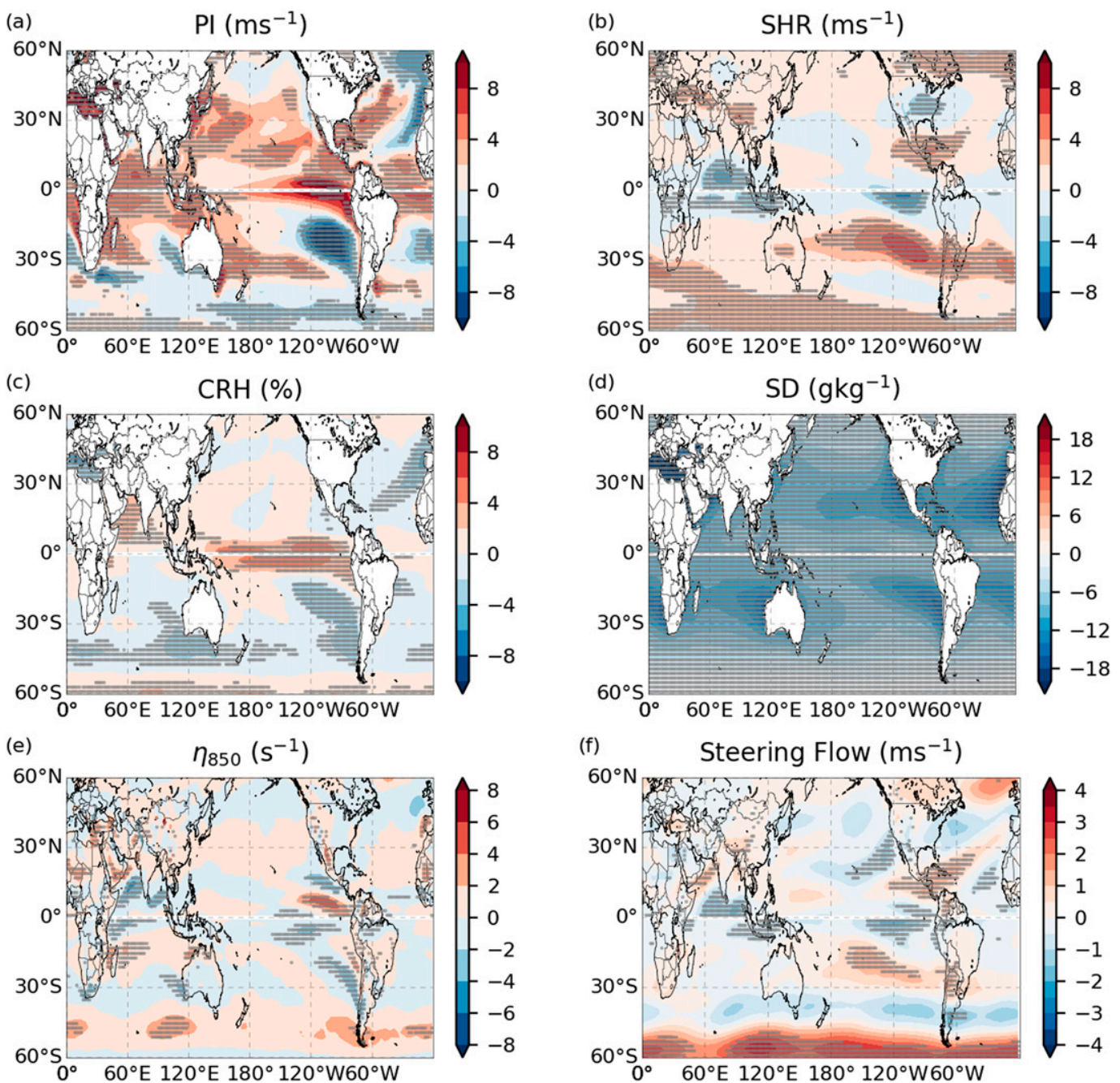

FIG. 1. Differences in the large-scale environment used in the CHAZ model between the historical period and the late twenty-first century on a $2^{\circ} \times 2^{\circ}$ grid spacing during the TC season. In the Northern Hemisphere, the environmental fields are averaged over May-November while in the Southern Hemisphere they are averaged over December-April. Gray dots show regions where the difference is larger than one standard deviation of the data from historical period.

lifetime maximum intensity (LMI) associated with RI (Lee et al. 2018, 2016b).

\section{Large-scale environments in the CMIP5 models}

Before analyzing the $\mathrm{CHAZ}$ results, we investigate the changes in large-scale environmental parameters simulated by the CMIP5 models from the historical to the late twenty-first-century periods. Changes in environmental conditions relevant to TC activity in a warming climate under the RCP8.5 scenario in individual CMIP5 models have been discussed in a few previous studies (Camargo 2013; Park et al. 2017). Our analyses focus on ensemble-averaged differences of the six variables used in the CHAZ model (Fig. 1). We use only the data during the TC seasons, namely, May-November for the North Hemisphere and December-April for South Hemisphere. Differences are considered to be significant, as indicated with gray dots in Fig. 1, if they exceed the ensemble standard deviation.

Similar to findings from previous studies (e.g., Yu et al. 2010; Camargo 2013), Fig. 1a shows that PI increases with warming throughout most of the tropics and subtropics. The exceptions are the eastern North Pacific and South Atlantic basins, where PI decreases. Since few storms have formed in these basins in recent history, the decreases in these basins are presumably of little relevance to future TC activity. The largest increase is found over the equatorial eastern Pacific, where the mean values of PI increases by as much as $10 \mathrm{~m} \mathrm{~s}^{-1}$, suggesting an El Niño-like pattern in the future. This El Niñolike pattern is documented in many previous studies 
(e.g., Vecchi and Soden 2007; Vecchi et al. 2008). Changes in the SHR and $\eta_{850}$ are significant in a few localized regions. The increase in vertical wind shear over the Caribbean Sea and southern part of Gulf of Mexico (Fig. 1b), as well as the increase in the low-level vorticity over the equatorial and eastern North Pacific (Fig. 1e) are possibly related to the El Niño-like pattern, as El Niño shifts the rising branch of the Walker circulation eastward and enhances the deep convection over the equatorial Pacific (Park et al. 2017). A recent work by Seager et al. (2019) found that such pattern may be in error, as a consequence of the models' well-known cold tongue double-ITCZ biases. Nevertheless, our results from the six models used here are overall consistent with the 14model CMIP5 multimodel ensemble-mean differences shown in Camargo (2013).

The middle panels of Fig. 1 compare changes in the two moisture variables used in TCGI experiments. Changes in the CRH are modest in amplitude and nonuniform in sign, while those of SD are substantial and everywhere negative. SD and CRH have very similar spatial patterns in the current climate (not shown). Both describe how far the atmosphere is from saturation, but they do so differently: CRH represents the ratio between water vapor and saturated water vapor pressure, while SD is the absolute difference. As saturated water vapor increases with the temperature, $\mathrm{CRH}$ remains close to constant (e.g., Held and Soden 2006; Sherwood et al. 2010; Wright et al. 2010) and SD decreases (Camargo et al. 2014). As an example, Fig. 2 shows the temperature dependences of SD and CRH from GFDL CM3 simulations using the area-average values over all longitudes from $0^{\circ}$ to $40^{\circ} \mathrm{N}$. The same difference holds at individual grid points. Thus, it is difficult to determine which is a better variable to use in TCGI from historical observations, while nonetheless the two behave very differently under global warming. We will see below that the difference has large consequences for TC frequency.

Changes in the steering flow [Eq. (1)] are shown in Fig. 1f. The steering flow over the near-equatorial north Indian Ocean shows a significant decrease, suggesting that storm translation speeds should decrease here. In contrast, the steering flow increases over the northern part of that basin. An increase in the steering flow also occurs over the Caribbean Sea. In other TC basins, changes in the steering flow are small in magnitude and spatially variable in sign.

\section{Two plausible changes in the annual TC frequency}

\section{a. Global perspective}

Time series of the annual TC frequency from the two sets of CHAZ simulations with different humidity

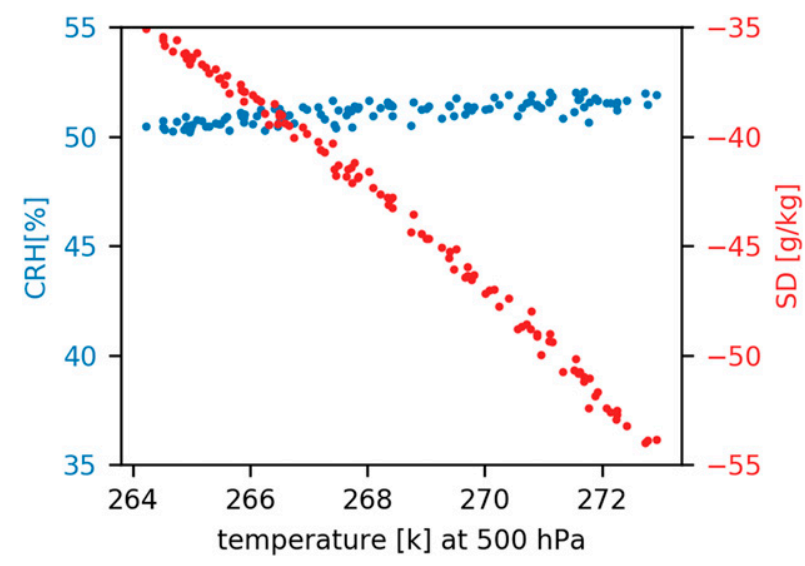

FIG. 2. Scatterplots of Northern Hemisphere $\left(0^{\circ}-40^{\circ} \mathrm{N}\right)$ seasonalmean midlevel $(500 \mathrm{hPa})$ atmospheric temperature $(\mathrm{K})$ vs $\mathrm{SD}$ and CRH. Data are from GFDL CM3.

variables (Fig. 3a) diverge in the future. In the TCGI_CRH experiments, the global-mean TC frequency increases by roughly 35 storms from the historical period to the end of the twenty-first century, with a mean rate of increase of 0.31 storms per year. In the TCGI_SD experiments, the multimodel, global mean annual TC frequency drops by roughly 0.63 storms per year, a reduction of around 60 storms by 2100 . This bifurcation is due to differences in the seeding rate in TCGI (Fig. 3b) that depend on the choice of humidity variable. In Eq. (2), changes in PI dominate and result in increasing $\mu$ as the climate warms. Using our results in Eq. (3), the influence of SD surpasses that of PI and leads to a large reduction in $\mu$. This finding is consistent with Camargo et al. (2014) as discussed in section $2 b$. While the sign of the projected tendency is not sensitive to the choice of the CMIP5 model being downscaled, the magnitude of the change is (Table 1). Among the six CMIP5 models used here, in the TCGI_CRH experiments, GFDL CM3 shows the largest rate of increase, 0.56 storms per year, while MRI-CGCM3 has the smallest, 0.07 storms per year. In the TCGI_SD experiments, the GFDL CM3 and HadGEM2-ES models decrease at rates greater than 0.7 storms per year while MIROC5 has the smallest rate of decrease, 0.5 storms per year. For reference, the trends in the directly simulated TC frequencies in these CMIP5 models used here, as shown in Camargo (2013), are decreasing in the GFDL CM3 (30\%), HadGEM2ES (50\%), and MIROC5 (50\%) models, and increasing in MPI-ESM-MR (20\%) and MRI-CGCM3 (30\%). The changing rates in parentheses are rough estimates from medians in Fig. 7 in Camargo (2013). Note that the numbers of storms shown in these low-resolution models are sensitive to the tracking routines used to detect them. For example, Camargo (2013) found that CCSM4 
(a)

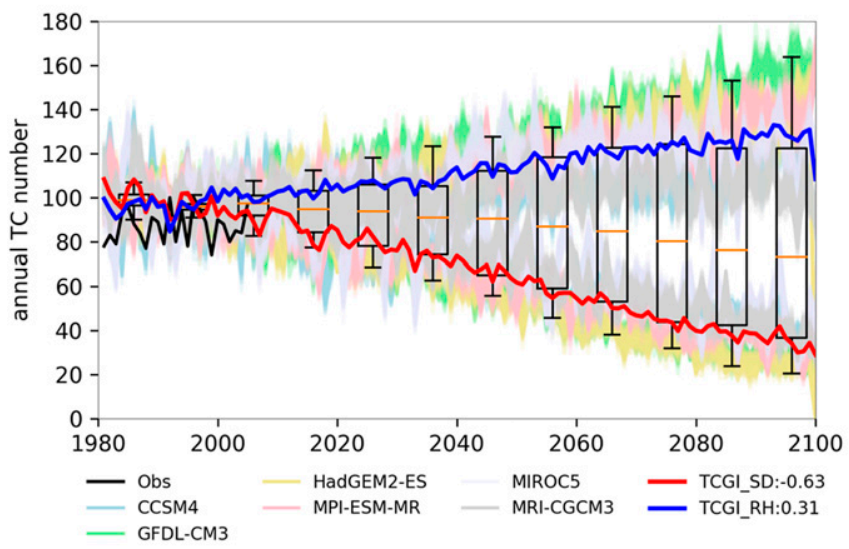

(b)

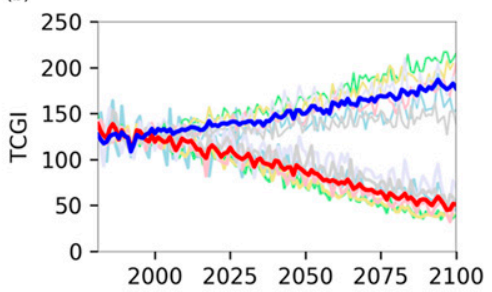

(c)

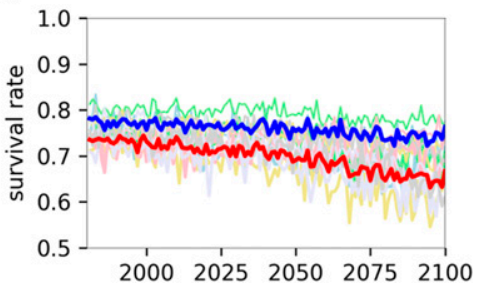

FIG. 3. Time series of (a) the CHAZ-simulated annual global TC frequency, (b) the TCGI-estimated seeding rate, and (c) the survival rate of the synthetic storms. Thin lines show downscaling results from each of the CMIP5 models, indicated by color. The box-and-whisker diagram in (a) shows the median (orange) and the 5th, 25th, 75th, and 95th percentiles. The thick blue and red lines show the ensemble mean from the TCGI_CRH and TCGI_SD experiments, respectively.

produced too few storms to examine the changes with warming, but Tory et al. (2013) used a different tracking routine and found a reduction in $\mathrm{TC}$ frequency in the warming climate in that model.

Downscaling the same six CMIP5 models but using a different statistical-dynamical downscaling model, Emanuel (2013) found that the global TC frequency increases from 80-85 storms per year for the historical period to 120 storms per year (ranges from 90 to 125 storms per year) at 2100. One of the differences between our methods and Emanuel's is that we use TCGI to determine our seeding rate while he uses a random seeding approach with a globally uniform rate. The TC frequency (genesis rate) in both models can be seen as a combination of the seeding rate, that is, the rate at which precursors that are inserted initially, and the survival rate, that is, ratio of storms that intensified from these precursors. In Emanuel's approach, the increasing trend in CMIP5 is due to changes in the survival rate, because the seeding rate does not change. The warming climate allows more vortices to intensify and grow into mature storms. In our approach, changes in the TC annual frequency are due to changes in the seeding rate (Fig. 3b). The slopes (Table 1) of the trends of the annual TC frequency and seeding rate are slightly different, though, because the survival rate changes as well, if only slightly. In both experiments, the survival rate (Fig. 3c) decreases, implying that if the random seeding technique is used in the CHAZ - a target for future work-we may find a reduction in the annual TC frequency. It is worth noting here that the recent finding of an increase in TC count from the $25-\mathrm{km}$ resolution GCM by Bhatia et al. (2018), discussed in the introduction (section 1), is attributed to an increase in the number of precursors (Vecchi et al. 2019).

The ensemble-mean annual frequency over all the experiments, including both TCGI_CRH and TCGI_SD (orange lines in Fig. 3a), is arguably not meaningful, because no individual model simulation comes near it. This leaves us in a challenging situation. As both versions of TCGI yield similar results for the historical period, we cannot determine from historical evidence which of the two is more correct. There is a theoretical argument for using SD (Emanuel et al. 2008): SD better

TABLE 1. Changes in the annual frequency and TCGI seeding rate (number of storms per year)

\begin{tabular}{|c|c|c|c|c|c|c|}
\hline & CCSM4 & GFDL CM3 & HadGEM2-ES & MPI-ESM-MR & MIROC5 & MRI-CGCM3 \\
\hline \multicolumn{7}{|c|}{ Annual frequency } \\
\hline TCGI_CRH & 0.19 & 0.56 & 0.34 & 0.40 & 0.28 & 0.07 \\
\hline TCGI_SD & -0.59 & -0.73 & $\begin{array}{l}\quad-0.75 \\
\text { TCGI seeding rate }\end{array}$ & -0.64 & -0.51 & -0.59 \\
\hline TCGI_CRH & 0.34 & 0.80 & 0.68 & 0.49 & 0.62 & 0.21 \\
\hline TCGI_SD & -0.68 & -0.89 & -0.89 & -0.81 & -0.55 & -0.66 \\
\hline
\end{tabular}


reflects the increase in the thermodynamic inhibition of TC formation in a warming climate; more surface fluxes are required to saturate the column on mesoscale, a prerequisite to genesis (Emanuel 2018). However, this argument has not been articulated in detail nor tested in any demanding way, and we do not view it as adequate to settle the matter-particularly when the best global high-resolution dynamical simulations are similarly equivocal to our results, with the latest results from Bhatia et al. (2018) and Vecchi et al. (2019) showing an increase and others showing decreases.

Unlike the case with intensity, where PI theory offers some guidance (Bister and Emanuel 2002), or precipitation, where increases are very robustly supported by a range of evidence (e.g., Knutson et al. 2010), there is no general theory for TC frequency on either a basin or global scale that we might use to guide our interpretation of numerical model results (e.g., Walsh et al. 2016). The bottom line is that, as far as we can tell, there are two very distinct but possible scenarios, or "storylines" (Shepherd 2016; Shepherd et al. 2018) of future changes in TC frequency. The uncertainty is epistemic, and we cannot assign probabilities to the two storylines other than saying that we cannot rule out either one. Given this current state of knowledge, we can and should explore the consequent changes in other aspects of the TC climatology and hazard corresponding to these two different storylines.

\section{b. Basinwide perspective}

For individual basins, the bifurcation between the TCGI_CRH and TCGI_SD experiments (left panels in Figs. 4 and 5) is not as dramatic as it is globally (Fig. 3). In the Atlantic, the eastern North Pacific, north Indian Ocean, south Indian Ocean, and northern Australia, the lowest 5th-25th percentiles of the annual frequency distributions for TCGI_CRH overlap with the 75th95th percentiles in the TCGI_SD experiments. We can still see a clear divergence between the two sets of experiments, however.

The right panels in Figs. 4 and 5 show the distribution of the annual TC frequency from observations and simulations from the historical period (HIST) and late twenty-first century (RCP85). For each curve, the mean is marked by a dotted line. Since the means of the HIST results are adjusted toward the observations, they have the same values (black dotted line) by construction. While we correct only the mean values for genesis, the simulated distributions (colored dashed curves) are close to those from observations (black curves) in the Atlantic, eastern North Pacific, and northern Australian regions, indicating that the CHAZ model successfully reproduces the differing observed interannual frequency in these regions. Over the western North Pacific and the north and south Indian Ocean, CHAZ overestimates the probabilities in the tails of the distributions of the formation rates. In the South Pacific, CHAZ underestimates the chance of more than 18 storms in a year.

The distributions of annual TC frequency in the RCP85 from the TCGI_CRH experiments are shifted toward the right relative to the historical period (comparing the dashed blue lines to the solid blue lines in the right panels in Figs. 4 and 5), consistent with the increasing trends in frequency in those experiments. In the western North Pacific, the rate of increase is 0.12 storms per year, and the mean annual TC frequency increases from 25.44 storms per year in the current climate to 37.85 storms per year by the late twenty-first century $(50 \%)$. The mean number increases by 7.27 storms per year $(40 \%)$ in the eastern North Pacific, and by 2.95 (62\%), 2.75 (25\%), $1.79(20 \%), 1.55(12 \%)$, and 0.98 $(16 \%)$ storms per year in the north Indian Ocean, northern Australia, south Indian Ocean, North Atlantic, and South Pacific, respectively. Relatively speaking, the north Indian Ocean has the largest rate of increase, followed by the Pacific basins. In most TC basins, the $100-y r$ values (those that occur with $1 \%$ probability in a given year) of the mean annual TC frequency in the historical period become about 10 times more likely by the late twenty-first century. Increases in the extreme values of Atlantic annual frequency are smaller than those in other basins. When SD is used in the TCGI, the mean frequencies decrease, as expected from the global results above, and the distributions of annual TC freqeuncy in the late twenty-first century shift left accordingly. The rates of decrease are larger than the increasing rate in the TCGI_CRH experiments in all basins except in the north Indian Ocean, where there is no room for large reductions (in an absolute sense) in the TC frequency since the numbers in the historical climate are already low. The largest rates of decrease occur in the two northern Pacific basins where the mean frequencies drop by 13.3 and 9.06 storms per year over the western and eastern North Pacific, respectively. In contrast to the TCGI_CRH results, which show a wide range in the rates of increase across basins, the fractional rates of decrease in the TCGI_SD results are all around $50 \%$ with, the largest decrease, $66 \%$, in the Atlantic.

\section{Changes in the TC tracks and intensity}

\section{a. Track pattern}

To examine changes in the track patten, we calculate track density using TC occurrence on $5^{\circ} \times 5^{\circ}$ grid per year. The projected changes (Fig. 6), at least in sign, simply reflect the changes in the TC frequency. Patterns 

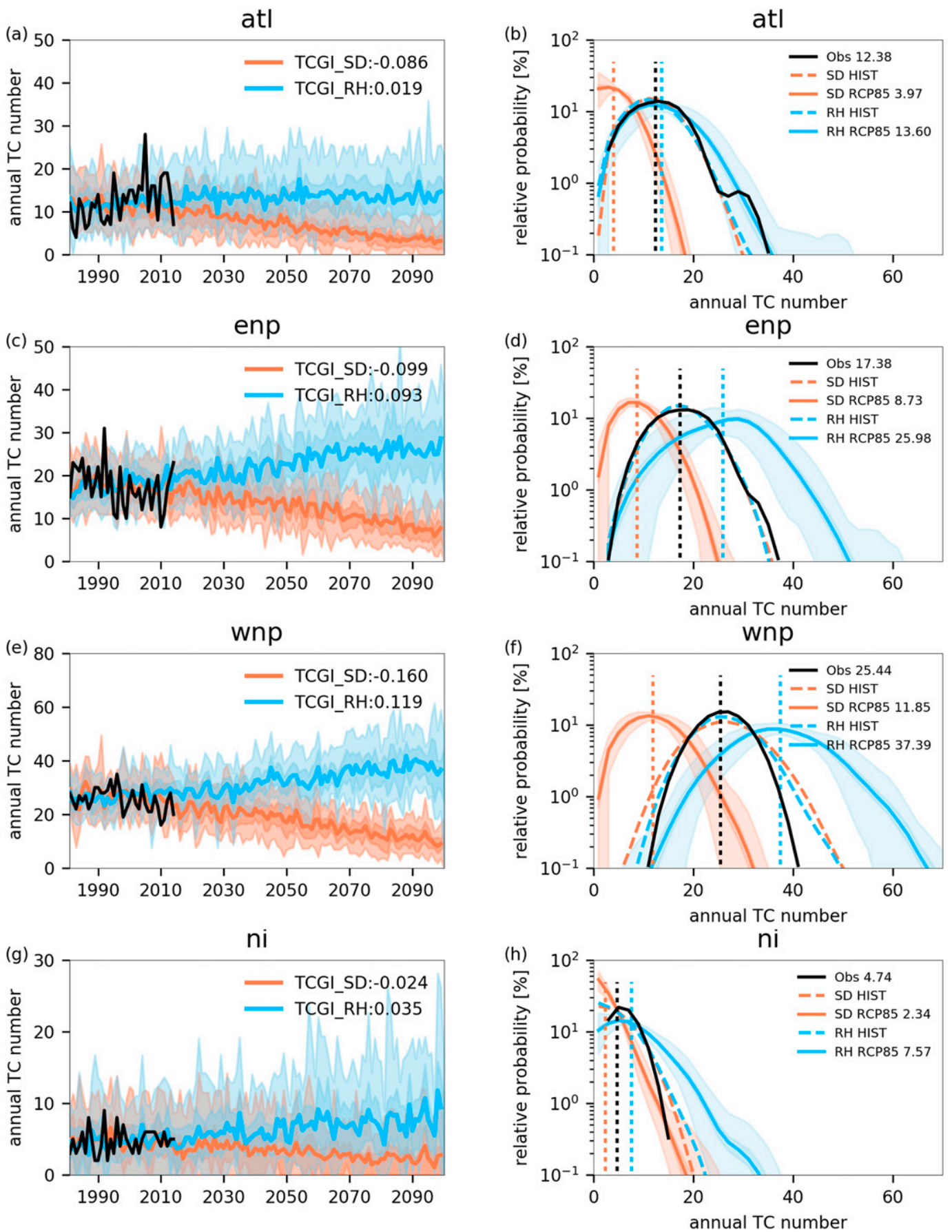

FIG. 4. (a),(c),(e),(g) Time series of annual-mean frequency for four Northern Hemisphere TC basins. Legends show the slope of the trend. (b),(d),(f),(h) Relative probability of the annual TC frequency from observations (black solid line) and the HIST (colored dashed line) and RCP85 (colored solid line) simulations. Shading indicates the confidence interval using bootstrapping 400 times with half of the ensemble members and with $10 \%$ of the members. In all panels the bluish color shows results from TCGI_CRH while the orangish color shows those in TCGI_SD.

in Fig. 6a, which shows TCGI_RH results, are dominated by results from GFDL CM3, the CMIP5 model with the largest upward trend. On the regional scale, there is a greater model to model variability. Using
$\mathrm{CRH}$ as the TCGI's moisture variable, more than four CMIP5 downscaling simulations agree on the positive trend (increase in TC frequency) over the western North Pacific, north Indian, and western south Indian Oceans, 

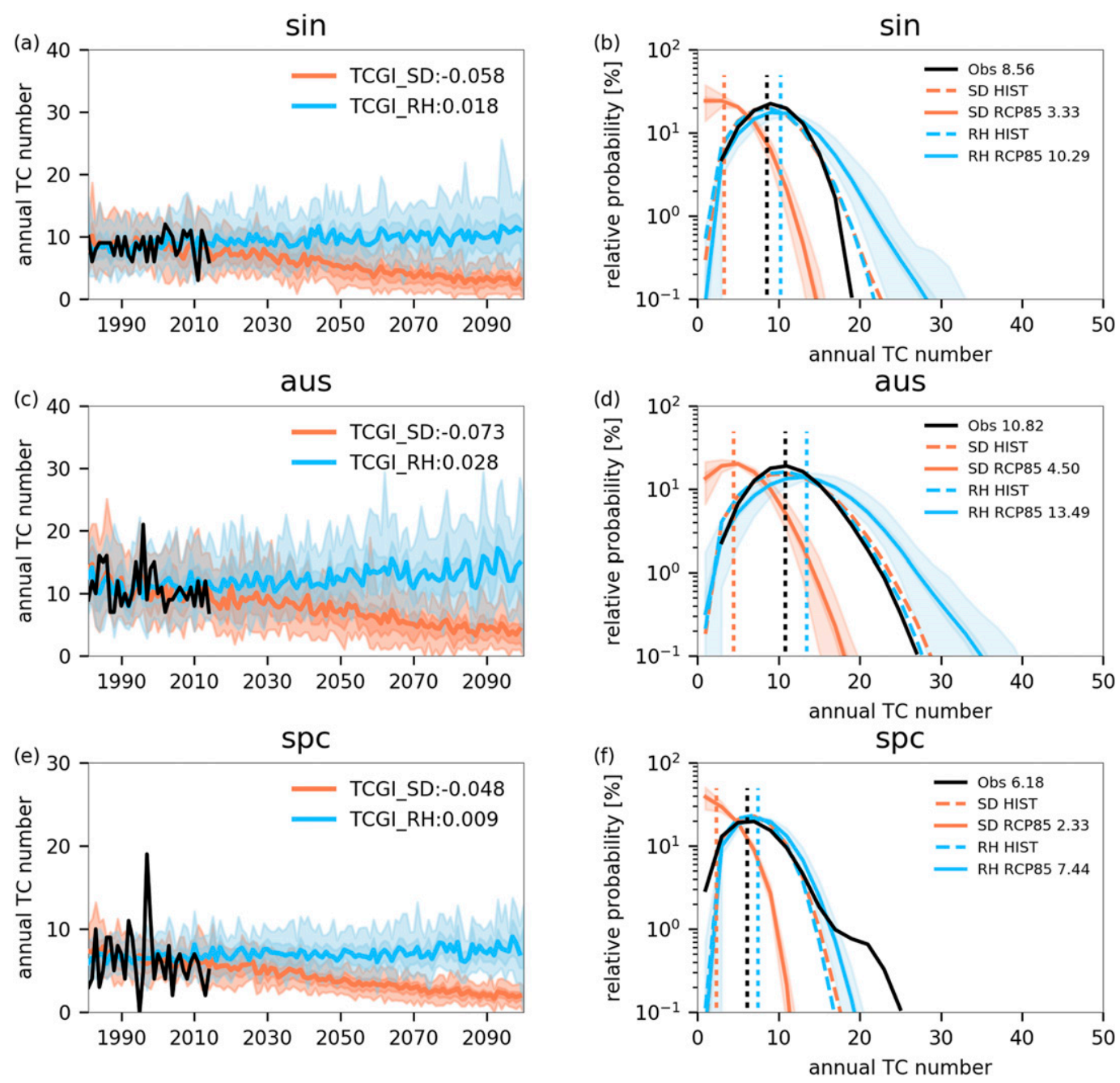

FIG. 5. As in Fig. 4, but for Southern Hemisphere TC basins.

as well as the South Pacific east of Australia. In the eastern to central North Pacific, North Atlantic, eastern south Indian Ocean, and central South Pacific, on the other hand, at least three CMIP5 downscaling simulations show no changes or decreasing trends. In the TCGI_SD experiment, results forced by all six CMIP5 models agree on a global declining trend.

\section{b. Changes in translation speed}

Another question of interest is whether TC translation speed is influenced by climate change, as suggested by Kossin (2018) based on observations. Here we consider this question using our CHAZ simulations. We consider only data from points near land, between $35^{\circ} \mathrm{N} / \mathrm{S}$, because of our interest in the hazard to human society. "Near land" is defined as when there is a landmass within $300-\mathrm{km}$ radius from the storm center. The restriction on the latitude in our analysis is to avoid the inclusion of storms expected to undergo extratropical transition.

The relative probability distribution in Fig. 7 shows that the most frequent observed forward speed values lie in the range of $10-15 \mathrm{~km} \mathrm{~h}^{-1}$, with fewer than $10 \%$ of storms having translation speeds in the range of $0-5 \mathrm{~km} \mathrm{~h}^{-1}$. Those features are captured by the CHAZ model. Comparing the distributions from HIST and RCP85, the probabilities of translation speeds below $15 \mathrm{~km} \mathrm{~h}^{-1}$ increase by $1 \%-2 \%$ globally. The increase is quite small, and the range of one standard deviation from RCP85 overlaps those from HIST. The exact change in the probabilities varies by basin. We see similar increases in the North Atlantic and western and eastern North Pacific, but not in the Indian Ocean (Fig. 8). In the Southern Hemisphere TC basins, we see a slight increase in the probabilities of a slow-moving storm over the South Pacific and Australia area, but not 
(a)

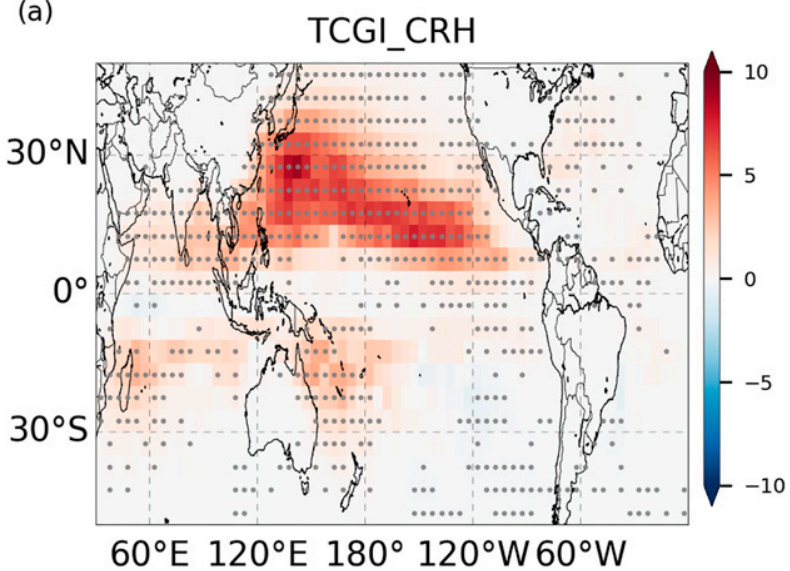

(b)

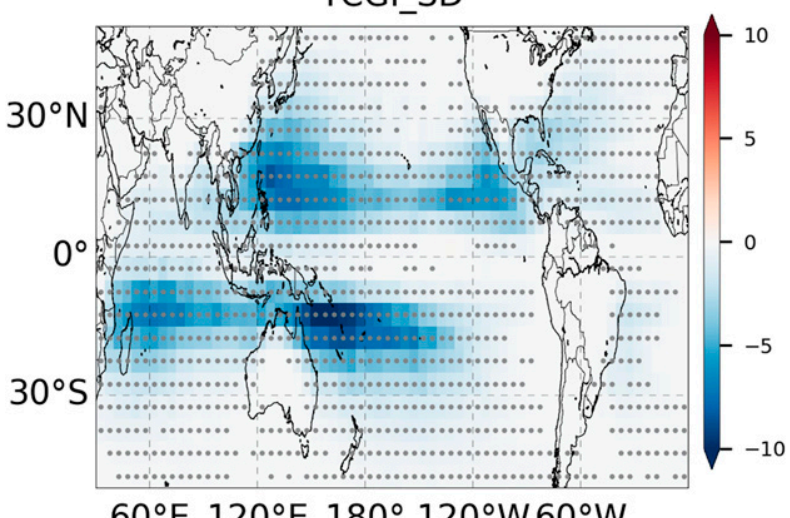

FIG. 6. Changes in the track density on a $5^{\circ} \times 5^{\circ}$ grid spacing in (a) TCGI_CRH and (b) TCGI_SD experiments. Gray dots are where at least four CMIP5 downscaling results show the same sign.

over the south Indian Ocean (not shown). The standard deviation of the translation speed from RCP85 is larger than from the HIST, indicating a larger variability in the large-scale wind fields among the CMIP5 models in a warming climate.

Trend analyses also suggest that there is a small decline in near-land forward speed, at least globally. From 1981 to 2100 , the slope of the global mean value is roughly $-6 \times 10^{-3} \mathrm{~km} \mathrm{~h}^{-1} \mathrm{yr}^{-1}$ in both TCGI_CRH and TCGI_SD experiments. While the decreasing trend, as well as the increasing probability of slow-moving TCs we find, is consistent in sign with the results of Kossin (2018) using observations from 1945 to 2014, the trend we find is much smaller. Trend analyses are sensitive to the beginning and ending year. With our near-land and latitude restrictions, the observed trend is $-0.097 \mathrm{~km} \mathrm{~h}^{-1} \mathrm{yr}^{-1}$ from 1945 to 2013 and $-0.021 \mathrm{~km} \mathrm{~h}^{-1} \mathrm{yr}^{-1}$ from 1981 to 2013 . The observed trend is also influenced by a few very slow-moving storms (Hall and Kossin 2019).

\section{c. Lifetime maximum intensity}

Next, we analyze the distributions of lifetime maximum intensity (LMI) as well as the numbers of major TCs (category 3 or greater) in the historical period and late twenty-first century (Fig. 9). In our simulations, changes in the number of major TCs largely reflect the changes in the total TC frequency. The ensemblemean annual frequency of major TC increases from 20 to 32 storms per year globally in the TCGI_CRH (blue lines), while it drops from 20 to 8 storms per year in the TCGI_SD. Similar results can be found for individual basins.

The fraction of TCs reaching high intensities, however, increases as the climate warms regardless of whether SD or CRH is used in the TCGI. The relative distribution of LMI in Figs. 10a and 10c shifts toward the right from the historical period (gray) to 2006-40 (green), 2041-70 (yellow), and the late twenty-first century (red). As discussed in section $2 \mathrm{a}$ and in Lee et al. (2016b), the shoulder feature in Figs. 10a and $10 \mathrm{c}$ ) is due to storms that undergo RI. The shift to the right in the LMI distribution means that the fraction of storms that undergo RI is increasing, which is shown in Figs. $10 \mathrm{~b}$ and 10d. The ensemble mean RI liklehood increases from $1 \%$ to $5 \%$ from the historical period to the late twenty-first century. The RI ratio slope is largest $\left(0.0267 \mathrm{yr}^{-1}\right)$ for the MPI-ESM-MR and smallest for the CCSM4. There is a decreasing trend for the MIROC5 results, but in all other models the RI ratio trend is in qualitative agreement with Bhatia et al. (2019).

The RI ratio trend varies by basin as well as the choice of forcing climate model. The largest increasing trends in the GFDL CM3 in Figs. 10b and 10d are due to storms over the Atlantic and eastern North Pacific (Fig. 11). Over the eastern North Pacific, storms from MPI-ESMMR and HadGEM2-ES also show large increasing trends but those from CCSM4 and MIROC5 in the TCGI_SD have decreasing trends. The increasing RI ratio trends in the Southern Hemisphere basins are smaller than in the Northern Hemispheric basins (Fig. 12).

Mean LMI latitude where TCs reach their peak intensity is observed being shifted in the past 30 years (Kossin et al. 2014). In the CHAZ (Table 2), we noticed a poleward migration projection globally, as well as in the Atlantic and the western and eastern North Pacific. Our results in the western North Pacific agree in sign with Kossin et al. (2016), who used synthetic storms from Emanuel's system (Emanuel 2013). CHAZ, however, has a smaller migration rate. It is $0.073^{\circ}$ and $0.049^{\circ}$ decade $^{-1}$ for TCGI_CRH and TCGI_SD experiments, 
(a)

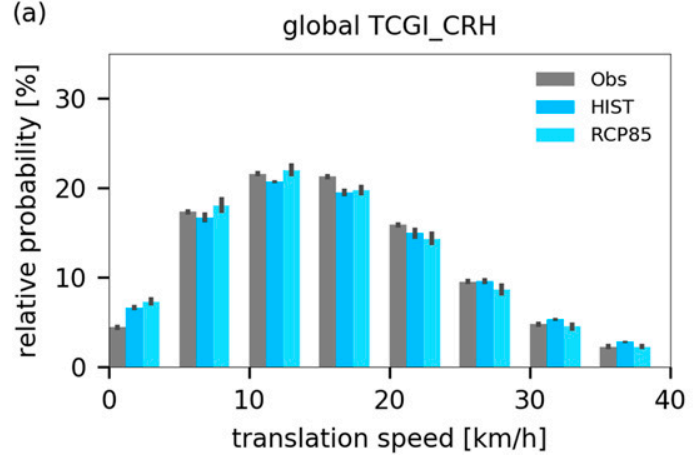

(b)

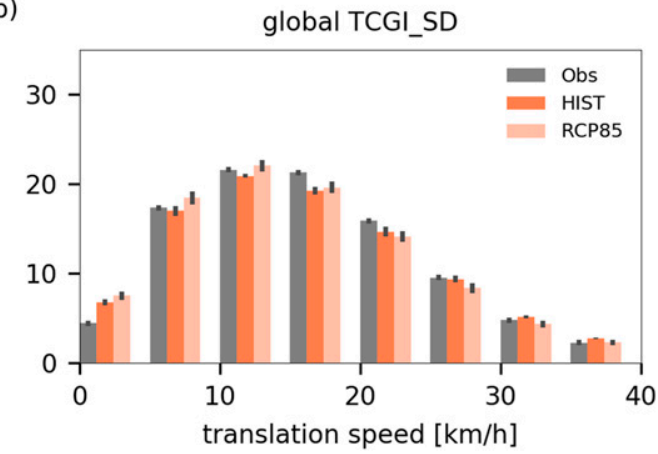

FIG. 7. The relative probabilities of storm forward speed globally from observations (gray) and synthetic storms from HIST and RCP85 in the (a) TCGI_CRH (bluish colors) and (b) TCG_SD (reddish colors). The ensemblemean distributions from HIST are shown in darker colors while those form RCP85 are in lighter colors. Vertical lines delineate one standard deviation.

respectively. The migration rate is $0.13^{\circ}$ decade $^{-1}$ in Kossin et al. (2016). For reference, the observed value is $0.15^{\circ}-0.18^{\circ}$ decade $^{-1}$ from 1980 to 2013 . The projected poleward migrations in both Atlantic and eastern North Pacific from CHAZ are inconsistent to the recent observed trend. Detailed analyses are required in the future in order to explain the above differences.

\section{Return periods}

We compute return period curves for wind speed on $3.6^{\circ} \times 1.8^{\circ}$ grids to describe the comprehensive impact of climate change on TC hazard at the regional scale. The return period is defined as the mean recurrence interval for an event exceeding a given threshold anywhere within a specific area, assuming stationary statistics, or equivalently the inverse of the annual probability of an event exceeding that threshold. The return period, while being widely used, does not consider other storm characteristics that are crucial to regional storm hazard, such as storm size and forward speed. Recent work by Stern et al. (2017) suggested that it would be better to include impact from storms in the surrounding area of the point in question; Stansfield et al. (2020) calculated track density as the number of hours per year the point in question is impacted by TCs. We acknowledge the importance of these factors but stick with the conventional return period definition to understand the first-order changes in the regional TC hazards.

Here, we use 6-hourly track data with a threshold of category 4 hurricane wind speed on the Saffir-Simpson scale $(113 \mathrm{kt})$. The underlying assumption of a return period calculation is that the record is much longer than the longest return periods being estimated. Estimates from observations are shown as a reference, but can only capture the shorter return periods (Fig. 13a). From observations, the probabilities of TCs with category 4 or stronger intensity are highest over the western Pacific (east of $120^{\circ} \mathrm{E}$ ), followed by the eastern North Pacific between $15^{\circ}$ and $20^{\circ} \mathrm{N}$ and west of $120^{\circ} \mathrm{W}$. Return periods from synthetic storms during the historical period have similar patterns to those observed, but over a wider area (Figs. 13b,c).

In the late twenty-first century, return periods from the TCGI_CRH experiments show an overall decrease, that is, increases in the annual probabilities (the reddish color in Fig. 13d). This is due to increases in both storm frequency and storm intensity. In the northern Gulf of Mexico, the annual numbers of category $4+$ TCs are decreasing and therefore the return periods over these areas are increasing. Changes in the return period of category $4+$ storms in the TCGI_SD experiments show an overall increase (i.e., decreases in the annual probabilities; bluish color in Fig. 13e), which is due to the reduction in TC frequency. We again notice a few localized areas where return periods of category $4+$ TCs are decreasing. Some high-resolution models that show a decrease in total TC frequency also show an increase in the frequency of category $4+$ TCs (corresponding to a decrease in the return period) in some regions (Knutson et al. 2015; Sugi et al. 2017; Yoshida et al. 2017).

\section{Conclusions}

We have used a statistical-dynamical downscaling approach to characterize the TC climatology and the consequent TC hazard under future climate projections. We downscale six CMIP5 models (CCSM4, GFDL CM3, HadGEM2-ES, MPI-ESM-MR, MIROC5, and 
(a)

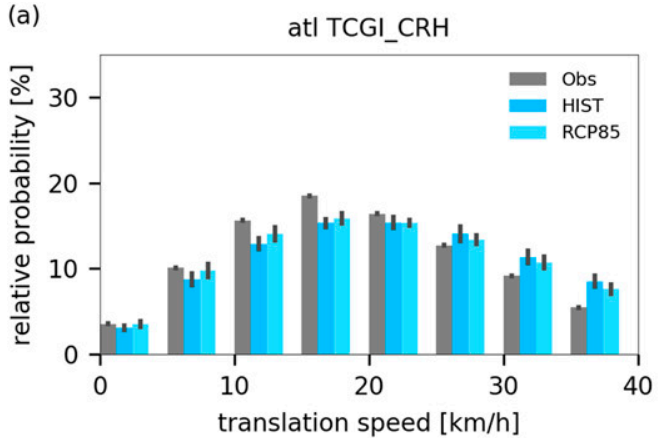

(c)

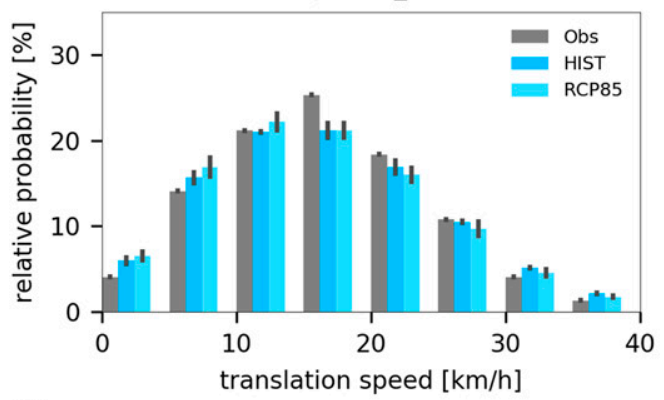

(e)

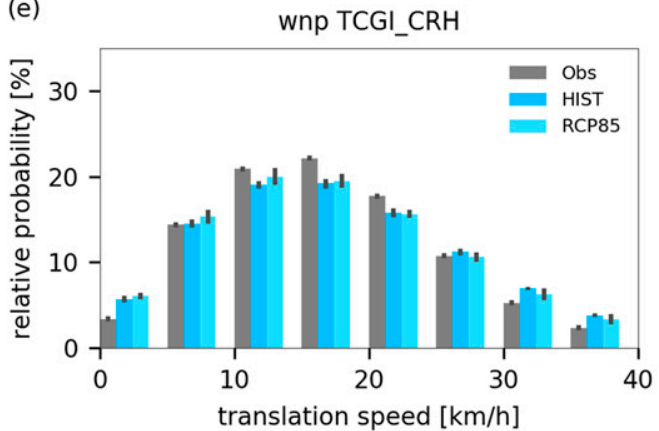

(g)

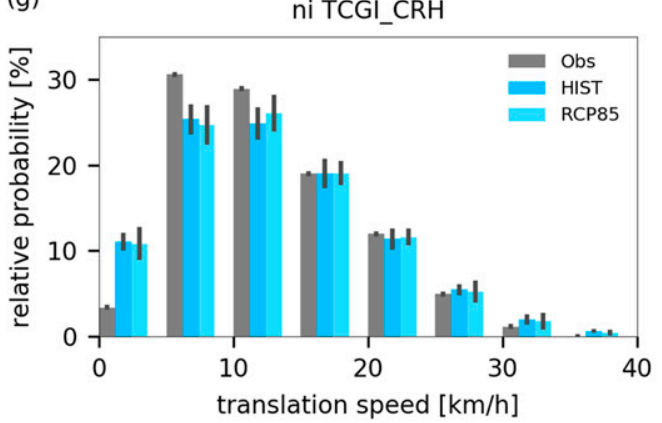

(b)

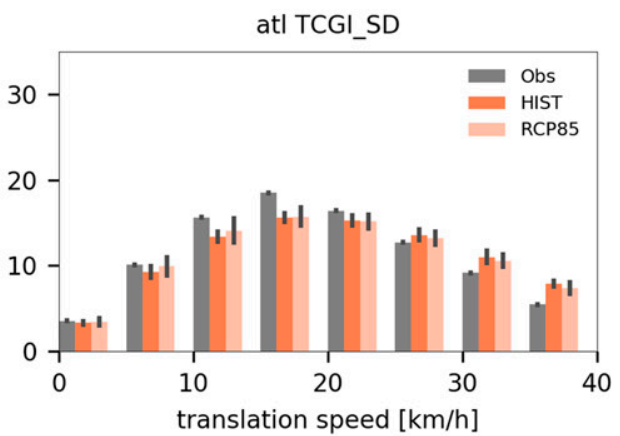

(d)

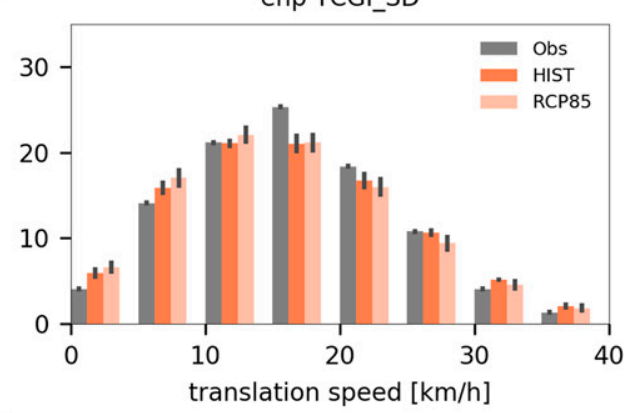

(f)

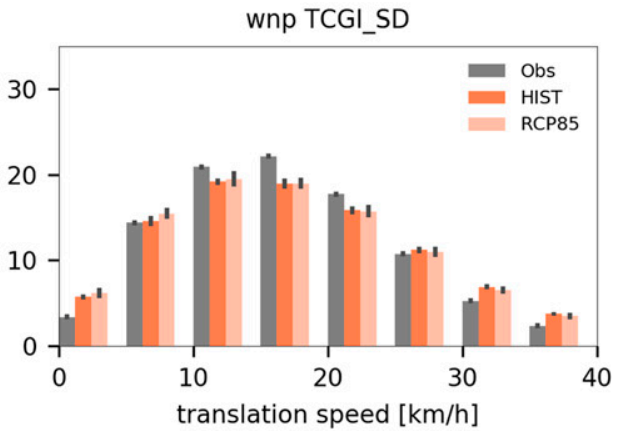

(h)

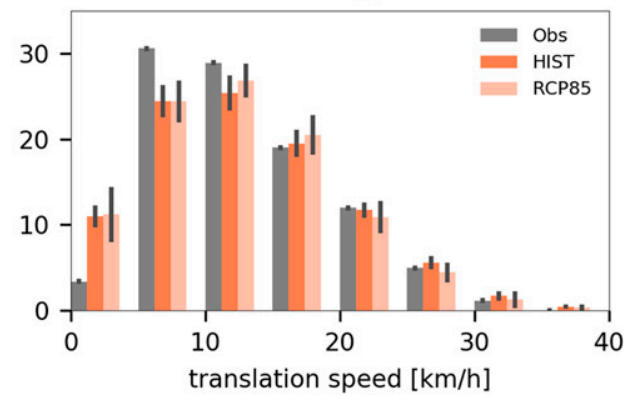

FIG. 8. As in Fig. 7, but for Northern Hemisphere TC basins.

MRI-CGCM3) using the CHAZ model. The large-scale predictors CHAZ uses are potential intensity (PI), deeplayer vertical wind shear (SHR), low-level vorticity, moisture variables [midlevel relative humidity and column-integrated relative humidity (CRH) or saturation deficit (SD)], and ambient steering winds. As the climate warms, PI increases significantly while SD decreases (Fig. 1). Changes in the other predictors are relatively small and spatially variable.

In the CHAZ simulations, the trend in TC frequency is controlled by the moisture variable used in the genesis component, TCGI. When CRH is used (experiment TCGI_CRH), there is an increasing trend in the projected annual-mean TC frequency (genesis rate), whereas 


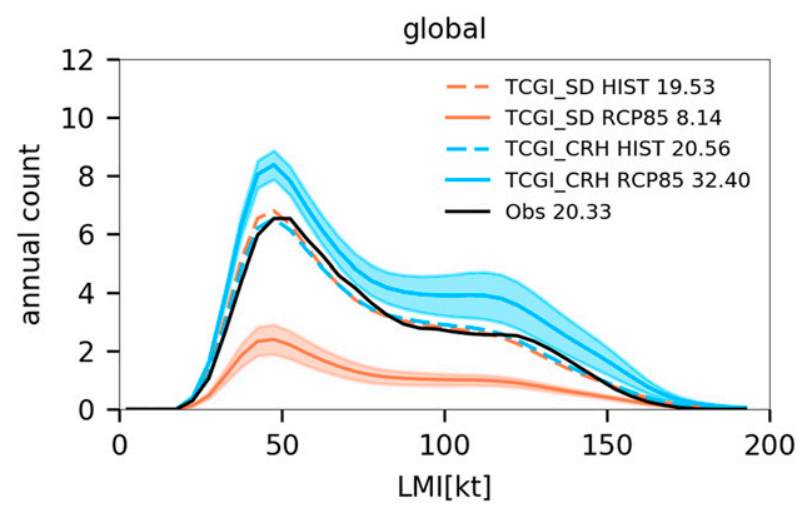

FIG. 9. The annual count for global storms' LMI from observations (black) and synthetic storms in the TCGI_CRH (bluish) and TCGI_SD (orange). Dashed blue and orange lines are the ensemble mean from HIST while the solid lines are from RCP85. The blue and orange shading show the ensemble spread for RCP85 simulations. Values in the legend indicate annual numbers of storms of Saffir-Simpison category 3 and above in each dataset.

when SD is used (experiment TCGI_SD) we see a declining trend (Fig. 3). This is true for all six CMIP5 models we have downscaled. While the choice of CMIP5 model providing the environmental fields has some influence on the results, the choice of humidity variable in the genesis index is more important. The divergence in the projected TC frequency trend is consistent with the results from the "perfect model" study by Camargo et al. (2014).

On the basin scale, the difference between the CRH and SD results is still present, but not as dramatic as on the global scale (Figs. 4 and 5). In the North Atlantic, the north and south Indian Oceans, and the northern Australian region, the bottom 10 th percentile of the simulated frequency has a declining trend in the TCGI CRH results and overlaps with those in the top 10th percentile of the TCGI_SD results. The changes in the annual TC frequency are important because they affect not only the projected TC occurrence (e.g., as manifest in track density; Fig. 6) but also other measures that combine frequency and intensity and that are important for the overall hazard, such as the numbers of storms exceeding high intensity thresholds (Fig. 9).

Other aspects of TC climatology, such as the annualmean storm forward speed and frequency-independent measures of intensity (e.g., the mean LMI, fraction of major TCs, and fraction of storms undergoing RI), are not sensitive to the choice of CRH versus SD. Globally, we see a slight decreasing trend in the TC forward speed (Fig. 7), a small increasing trend in both LMI and RI
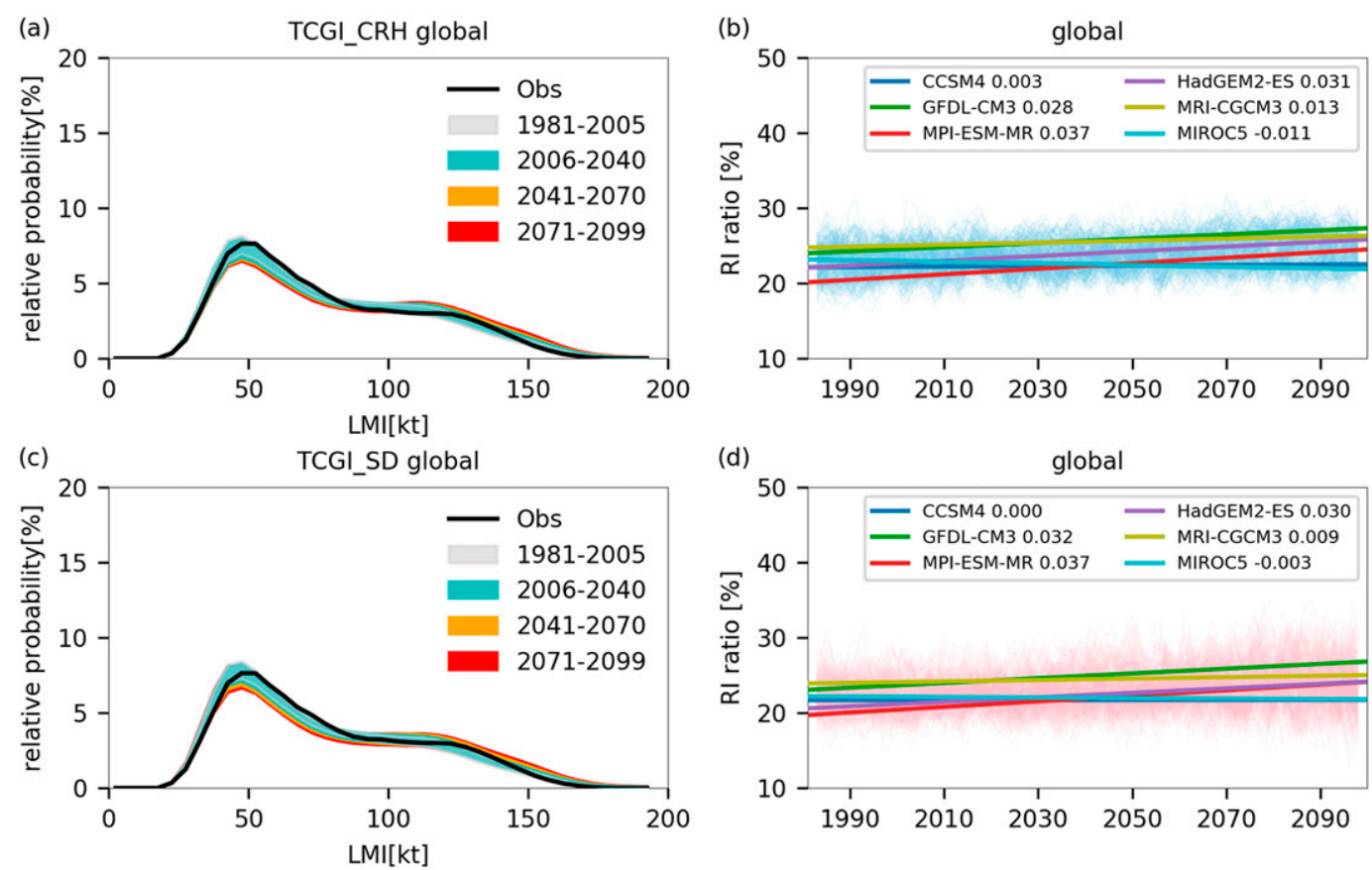

FIG. 10. (a) Relative probabilities of global LMI from observations (black) and CMIP5 synthetic storms in the TCGI_CRH experiment during historical periods (light gray), 2006-40 (green), 2041-70 (yellow), and 2070-99 (red). (b) Time series of RI ratio from CMIP5 synthetic storms in the TCGI_CRH experiments. The solid lines show the trends of the RI ratio from individual CMIP5 models, and the slope is indicated in the legend. (c),(d) As in (a) and (b), but for the TCGI_SD experiments. 
(a)

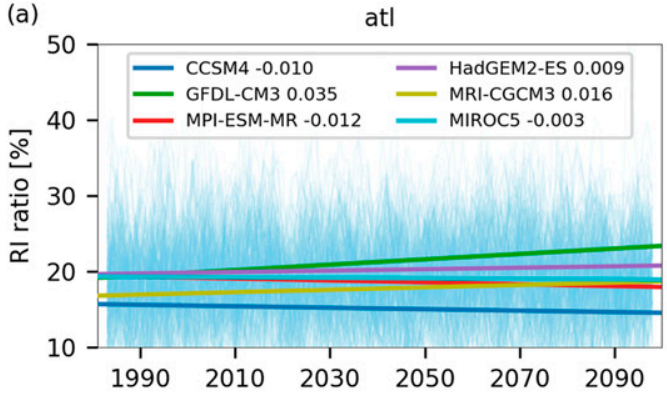

(c)

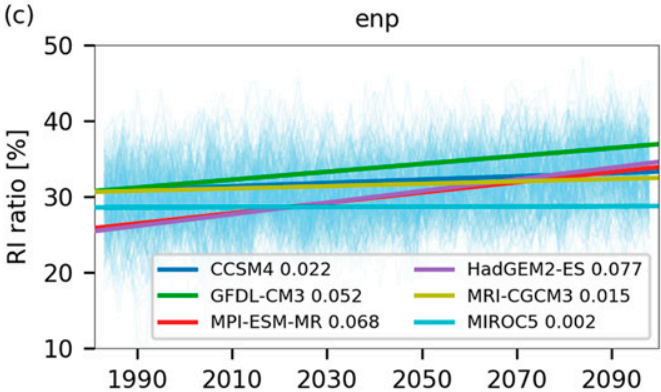

(e)

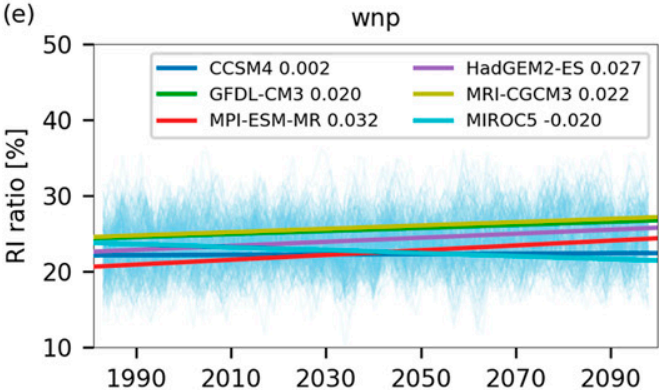

(g)

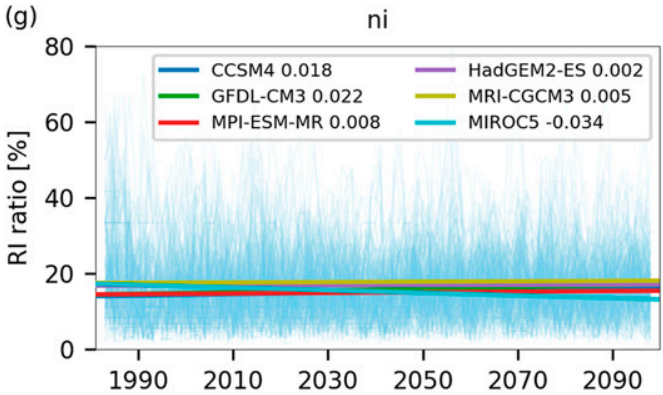

(b)

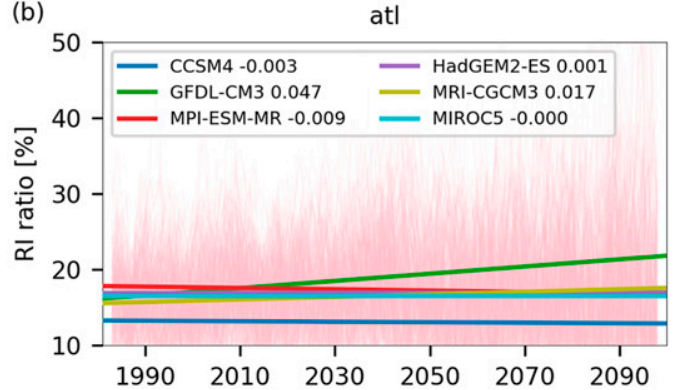

(d)

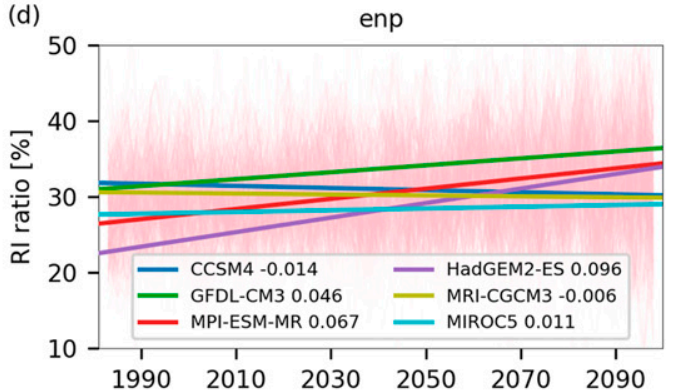

(f)

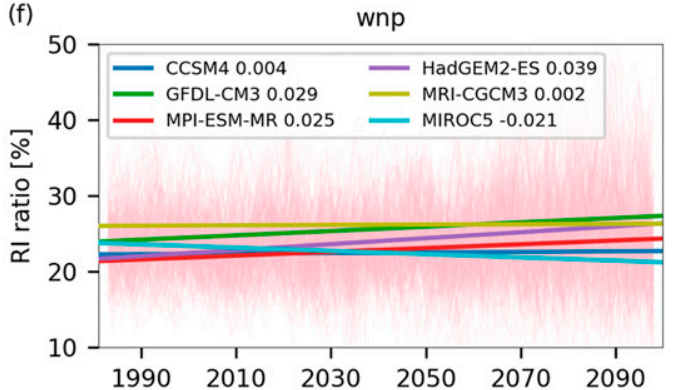

(h)

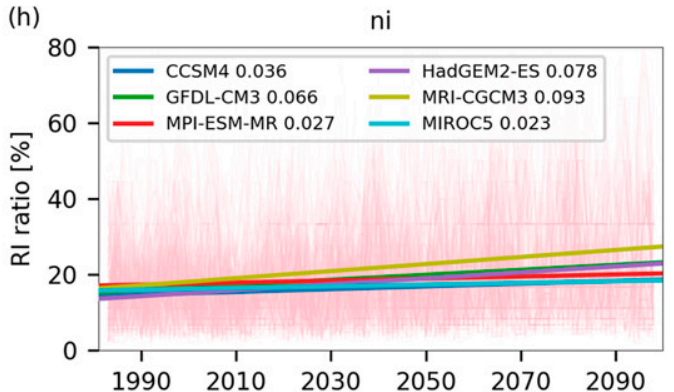

FIG. 11. Time series of RI ratio from CMIP5 synthetic storms in (left) TCGI_CRH and (right) TCGI_SD experiments in the Northern Hemisphere TC basins. The solid lines show the trends in the RI ratio from individual CMIP5 models, and the slope is indicated in the legend.

fraction (Fig. 10), and a notable poleward migration of LMI location (Table 2). On the basin scale, the relative probabilities of occurrence of slow-moving storms near land increase with warming over the Atlantic and eastern North Pacific, while there is no clear change in other basins (Fig. 8). The upward trend in the RI likelihood in the eastern to central Pacific is the largest compared to those in the other basins. The RI rate varies from one CMIP5 model to another, though, and GFDL CM3 results have a clearer upward trend (Figs. 11 and 12). The poleward migration of LMI is significant in the Atlantic and the western and eastern North Pacific (Table 2).

The bifurcation in the simulated trend in TC frequency is a challenging result. As both versions of TCGI 

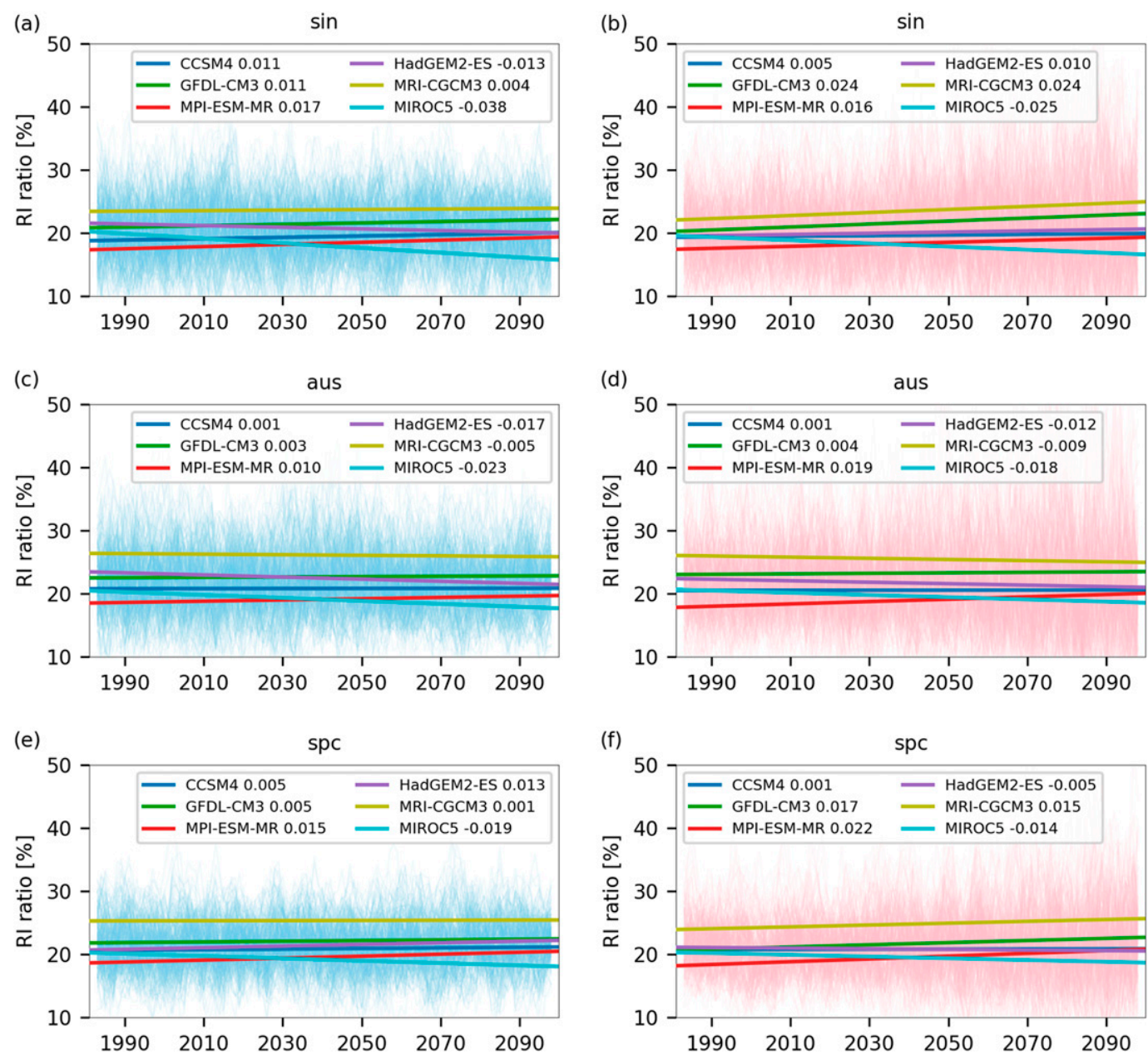

FIG. 12. As in Fig. 11, but for synthetic storms in the Southern Hemisphere TC basins.

yield similar results for the historical period, we cannot determine from historical evidence which of the two is more correct. While there is some theoretical basis to prefer SD to $\mathrm{CRH}$ as a humidity predictor, in our view it is not strong enough to be decisive. While it is deeply unsatisfying to find results that depend, qualitatively and strongly, on a choice of a predictor in an empirical genesis scheme, the resulting uncertainty-if not its cause-mirrors that currently found in the best state-ofthe-art global dynamical models, one of which shows increases in frequency while others show decreases. The large discrepancy in the projected annual TC frequency leads to discrepancies in regional and local storm hazard. The uncertainty here is fundamental and epistemic in nature, and not easily quantified; we have no basis for assigning probabilities that one or the other simulation is correct. This is a case where the "storyline" approach (Shepherd 2016; Shepherd et al. 2018), in which one considers different scenarios of climate change itself (as opposed to scenarios only of the socioeconomic drivers) without necessarily attaching probabilities to them, may be appropriate. This study also highlights the importance of improving our understanding of the fundamental physics controlling TC

TABLE 2. Changes in the multimodel, annual-mean LMI latitude in degrees per 100 years with $95 \%$ confidence intervals.

\begin{tabular}{|c|c|c|c|c|c|c|c|c|}
\hline & global & atl & enp & wnp & ni & $\sin$ & aus & $\mathrm{spc}$ \\
\hline TCGI_CRH & $0.31 \pm 0.06$ & $0.63 \pm 0.23$ & $0.87 \pm 0.10$ & $0.73 \pm 0.11$ & $-0.02 \pm 0.24$ & $0.57 \pm 0.14$ & $-0.07 \pm 0.12$ & $-0.14 \pm 0.18$ \\
\hline TCGI_SD & $0.10 \pm 0.08$ & $0.79 \pm 0.32$ & $0.72 \pm 0.13$ & $0.49 \pm 0.15$ & $-0.35 \pm 0.47$ & $0.08 \pm 0.19$ & $0.08 \pm 0.15$ & $-0.14 \pm 0.19$ \\
\hline
\end{tabular}




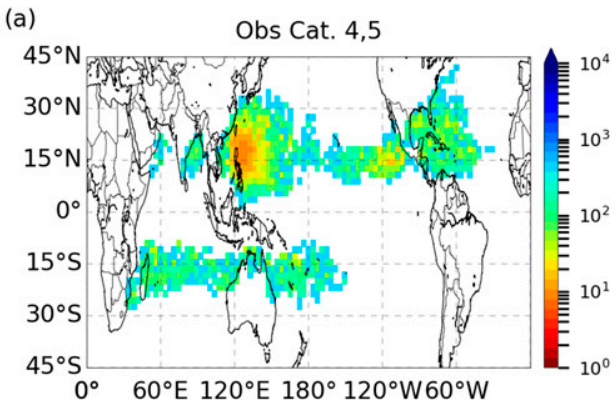

(b)

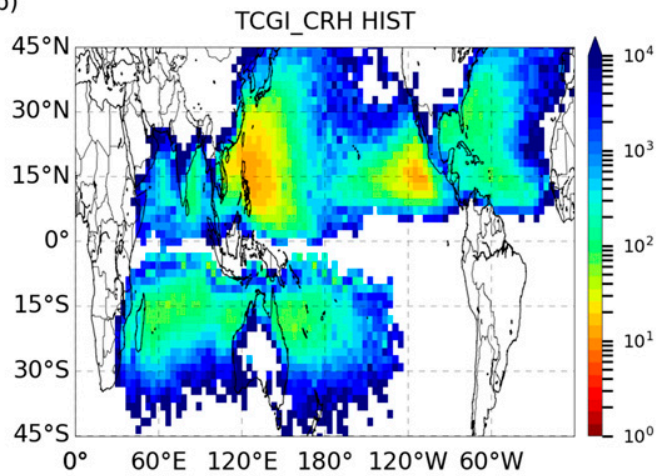

(d)

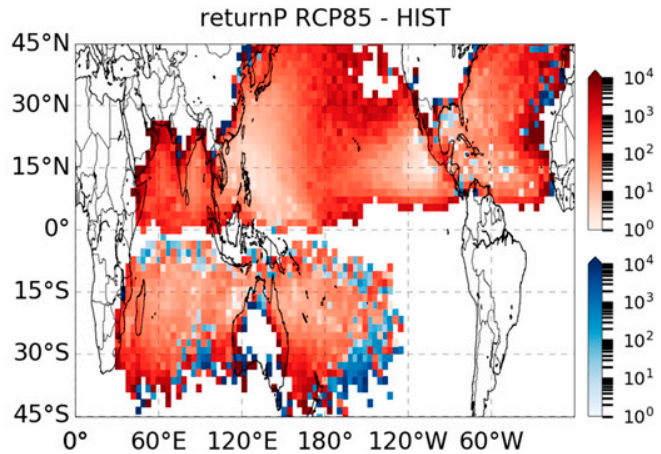

(c)

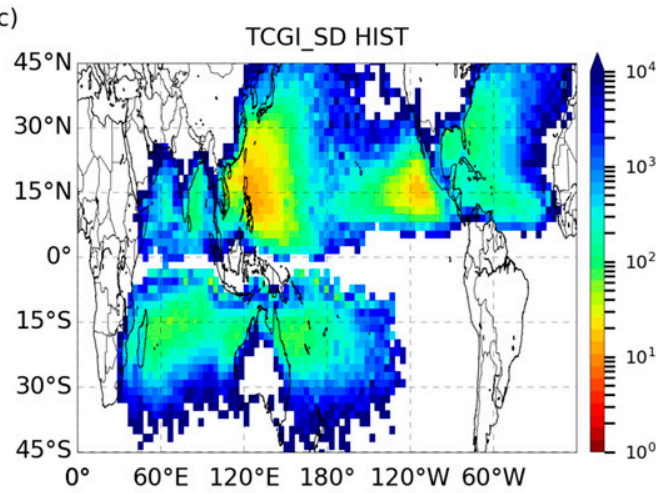

(e)

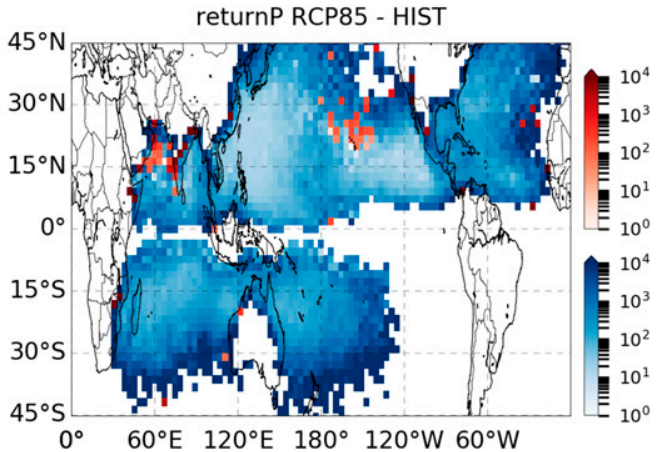

FIG. 13. (a) Return period map of storms exceeding category 4 hurricane strength (113 kt) based on 1981-2012 observations, calculated in $3.6^{\circ} \times 1.8^{\circ}$ boxes. (b) Return period map for storms exceeding category 4 hurricane strength from CMIP5 synthetic storms in the TCGI_CRH in the HIST period. (c) As in (b), but for TCGI_SD. (d),(e) Differences in return period maps between HIST and RCP85. Blue tones represent areas with increasing return period (less risk) while the red tones represent areas with decreasing return period (increasing risk) in the warming climate.

frequency (e.g., Walsh et al. 2016). Regardless of the changes in frequency, however, our results are consistent with other studies in indicating that those TC events that do occur will, on average, be more destructive in the future because of the robustly projected increases in intensity.

Acknowledgments. The research was supported by the New York State Energy Research and Development Authority under the research grant NYSERDA 103862.
Lee is also supported by Center for Climate and Life Fellowship, Columbia University. The authors declare no conflict of interest. Authors thank the three anonymous reviewers for their constructive suggestions and comments.

Data availability statement: CMIP5 data are archiving and available at https://esgf-node.llnl.gov. IBTrACS data are available at https://www.ncdc.noaa.gov/ibtracs/. The underlying $\mathrm{CHAZ}$ data for generating the figures are at https://github.com/c13225/JCLIM_2020/tree/v1.0.0, https://doi.org/10.5281/zenodo.3662728. 


\section{REFERENCES}

Bhatia, K., G. Vecchi, H. Murakami, S. Underwood, and J. Kossin, 2018: Projected response of tropical cyclone intensity and intensification in a global climate model. J. Climate, 31, 82818303, https://doi.org/10.1175/JCLI-D-17-0898.1.

— — - T. T. R. Knutson, H. Murakami, J. Kossin, K. W. Dixon, and C. E. Whitlock, 2019: Recent increases in tropical cyclone intensification rates. Nat. Commun., 10, 635, https://doi.org/ 10.1038/s41467-019-08471-z.

Bister, M., and K. A. Emanuel, 2002: Low frequency variability of tropical cyclone potential intensity 1 . Interannual to interdecadal variability. J. Geophys. Res., 107, 4801, https://doi.org/ 10.1029/2001JD000776.

Bretherton, C. S., M. E. Peters, and L. E. Back, 2004: Relationships between water vapor path and precipitation over the tropical oceans. J. Climate, 17, 1517-1528, https://doi.org/10.1175/15200442(2004)017<1517:RBWVPA>2.0.CO;2.

Camargo, S. J., 2013: Global and regional aspects of tropical cyclone activity in the CMIP5 models. J. Climate, 26, 9880-9902, https://doi.org/10.1175/JCLI-D-12-00549.1.

— , and A. A. Wing, 2016: Tropical cyclones in climate models. Wiley Interdiscip. Rev.: Climate Change, 7, 211-237, https:// doi.org/10.1002/WCC.373.

— A. W. Robertson, S. J. Gaffney, P. Smyth, and M. Ghil, 2007: Cluster analysis of typhoon tracks. Part I: General properties. J. Climate, 20, 3635-3653, https://doi.org/10.1175/JCLI4188.1.

— M. K. Tippett, A. H. Sobel, G. A. Vecchi, and M. Zhao, 2014: Testing the performance of tropical cyclone genesis indices in future climates using the HiRAM model. J. Climate, 27, 91719196, https://doi.org/10.1175/JCLI-D-13-00505.1.

Colbert, A. J., B. J. Soden, G. A. Vecchi, and B. P. Kirtman, 2013: The impact of anthropogenic climate change on North Atlantic cyclone tracks. J. Climate, 26, 4088-4095, https:// doi.org/10.1175/JCLI-D-12-00342.1.

Daloz, A. S., and Coauthors, 2015: Cluster analysis of downscaled and explicitly simulated North Atlantic tropical cyclone tracks. J. Climate, 28, 1333-1361, https://doi.org/10.1175/JCLID-13-00646.1.

DeMaria, M., M. Mainelli, L. K. Shay, J. A. Knaff, and J. Kaplan, 2005: Further improvements to the Statistical Hurricane Intensity Prediction Scheme (SHIPS). Wea. Forecasting, 20, 531-543, https://doi.org/10.1175/WAF862.1.

Donner, L. J., and Coauthors, 2011: The dynamical core, physical parameterizations, and basic simulation characteristics of the atmospheric component AM3 of the GFDL Global Coupled Model CM3. J. Climate, 24, 3484-3519, https://doi.org/10.1175/ 2011JCLI3955.1.

Emanuel, K. A., 2008: The hurricane-climate connection. Bull. Amer. Meteor. Soc., 89, ES10-ES20, https://doi.org/10.1175/ BAMS-89-5-EMANUEL.

_- 2013: Downscaling CMIP5 climate models shows increased tropical cyclone activity over the 21st century. Proc. Natl. Acad. Sci. USA, 110, 12 219-12 224, https://doi.org/10.1073/ pnas.1301293110.

_ 2017: Will global warming make hurricane forecasting more difficult? Bull. Amer. Meteor. Soc., 98, 495-501, https://doi.org/ 10.1175/BAMS-D-16-0134.1.

— 2018: 100 years of progress in tropical cyclone research. $A$ Century of Progress in Atmospheric and Related Sciences: Celebrating the American Meteorological Society Centennial, Meteor. Monogr., No. 59, Amer. Meteor. Soc., 15.1-15.68, https://doi.org/10.1175/AMSMONOGRAPHS-D-18-0016.1.
— - S. Ravela, E. Vivant, and C. Risi, 2006: A statistical deterministic approach to hurricane risk assessment. Bull. Amer. Meteor. Soc., 87, 299-314, https://doi.org/10.1175/ BAMS-87-3-299.

_ , R. Sundararajan, and J. Williams, 2008: Hurricanes and global warming: Results from downscaling IPCC AR4 simulations. Bull. Amer. Meteor. Soc., 89, 347-368, https://doi.org/ 10.1175/BAMS-89-3-347.

Fedorov, A. V., L. Muir, W. R. Boos, and J. Studholme, 2018: Tropical cyclogenesis in warm climates simulated by a cloudsystem resolving model. Climate Dyn., 52, 107-127, https:// doi.org/10.1007/s00382-018-4134-2.

Gent, P. R., and Coauthors, 2011: The Community Climate System Model version 4. J. Climate, 24, 4973-4991, https://doi.org/ 10.1175/2011JCLI4083.1.

Hall, T. M., and J. Kossin, 2019: Hurricane stalling along the North American coast and implications for rainfall. npj Climate Atmos. Sci., 2, 17, https://doi.org/10.1038/S41612-019-0074-8.

He, J., and B. J. Soden, 2015: Anthropogenic weakening of the tropical circulation: The relative roles of direct $\mathrm{CO}_{2}$ forcing and sea surface temperature change. J. Climate, 28, 8728-8742, https://doi.org/10.1175/JCLI-D-15-0205.1.

Held, I. M., and B. J. Soden, 2006: Robust responses of the hydrological cycle to global warming. J. Climate, 19, 5686-5699, https://doi.org/10.1175/JCLI3990.1.

_ - and M. Zhao, 2011: The response of tropical cyclone statistics to an increase in $\mathrm{CO}_{2}$ with fixed sea surface temperatures. J. Climate, 24, 5353-5364, https://doi.org/10.1175/JCLI-D-1100050.1.

IPCC, 2013: Climate Change 2013: The Physical Science Basis. Cambridge University Press, 1535 pp., https://doi.org/10.1017/ CBO9781107415324.

Jones, C. D., and Coauthors, 2011: The HadGEM2-ES implementation of CMIP5 centennial simulations. Geosci. Model Dev., 4, 543-570, https://doi.org/10.5194/gmd-4-543-2011.

Knapp, K. R., M. C. Kruk, D. H. Levinson, H. J. Diamond, and C. J. Neumann, 2010: The International Best Track Archive for Climate Stewardship (IBTrACS): Unifying tropical cyclone data. Bull. Amer. Meteor. Soc., 91, 363-376, https://doi.org/ 10.1175/2009BAMS2755.1.

Knutson, T. R., and Coauthors, 2010: Tropical cyclones and climate change. Nat. Geosci., 3, 157-163, https://doi.org/ 10.1038/ngeo779.

_ J. J. Sirutis, M. Zhao, R. E. Tuleya, M. Bender, G. A. Vecchi, G. Villarini, and D. Chavas, 2015: Global projections of intense tropical cyclone activity for the late twenty-first century from dynamical downscaling of CMIP5/RCP4.5 scenarios. J. Climate, 28, 7203-7224, https://doi.org/10.1175/JCLI-D-150129.1.

Kossin, J. P., 2018: A global slowdown of tropical-cyclone translation speed. Nature, 558, 104-107, https://doi.org/10.1038/ s41586-018-0158-3.

_ , K. A. Emanuel, and G. A. Vecchi, 2014: The poleward migration of the location of tropical cyclone maximum intensity. Nature, 509, 349-352, https://doi.org/10.1038/nature13278.

_ _ _ - and S. J. Camargo, 2016: Past and projected changes in western North Pacific tropical cyclone exposure. J. Climate, 29, 5725-5739, https://doi.org/10.1175/JCLI-D-16-0076.1.

Kowch, R., and K. Emanuel, 2015: Are special processes at work in the rapid intesification of tropical cyclones? Mon. Wea. Rev., 143, 878-882, https://doi.org/10.1175/MWR-D-14-00360.1.

Lee, C.-Y., M. K. Tippett, S. J. Camargo, and A. H. Sobel, 2015: Probabilistic multiple linear regression modeling for tropical 
cyclone intensity. Mon. Wea. Rev., 143, 933-954, https:// doi.org/10.1175/MWR-D-14-00171.1.

$\longrightarrow,-$, A. H. Sobel, and S. J. Camargo, 2016a: Autoregressive modeling for tropical cyclone intensity climatology. J. Climate, 29, 7815-7830, https://doi.org/10.1175/JCLI-D-15-0909.1.

,,--- , and — 2016b: Rapid intensification and the bimodal distribution of tropical cyclone intensity. Nat. Commun., 7, 10625, https://doi.org/10.1038/ncomms10625.

,,--- , and,- 2018 : An environmentally forced tropical cyclone hazard model. J. Adv. Model. Earth Syst., 10, 223-241, https://doi.org/10.1002/2017MS001186.

Ma, J., S.-P. Xie, and Y. Kosaka, 2012: Mechanisms for tropical tropospheric circulation change in response to global warming. J. Climate, 25, 2979-2994, https://doi.org/10.1175/JCLI-D-11-00048.1.

Murakami, H., and B. Wang, 2010: Future change of North Atlantic tropical cyclone tracks: Projection by a $20-\mathrm{km}-\mathrm{mesh}$ global atmospheric model. J. Climate, 23, 2699-2721, https:// doi.org/10.1175/2010JCLI3338.1.

Nakamura, J., and Coauthors, 2017: Western North Pacific tropical cyclone model tracks in present and future climates. J. Geophys. Res. Atmos., 122, 9721-9744, https://doi.org/ 10.1002/2017JD027007.

Park, D.-S. R., C.-H. Ho, J. C. L. Chan, K.-J. Ha, H.-S. Kim, J. Kim, and J.-H. Kim, 2017: Asymmetric response of tropical cyclone activity to global warming over the North Atlantic and western North Pacific from CMIP5 model projections. Sci. Rep., 7, 41354, https://doi.org/10.1038/srep41354.

Rappin, E. D., D. S. Nolan, and K. A. Emanuel, 2010: Thermodynamic control of tropical cyclogenesis in environments of radiative-convective equilibrium with shear. Quart. J. Roy. Meteor. Soc., 136, 1954-1971, https://doi.org/ 10.1002/qj.706.

Schreck, C. J., K. K. Knapp, and J. P. Kossin, 2014: The impact of best track discrepancies on global tropical cyclone climatologies using IBTrACS. Mon. Wea. Rev., 142, 3881-3899, https:// doi.org/10.1175/MWR-D-14-00021.1.

Seager, R., M. Cane, N. Henderson, D.-E. Lee, R. Abernathey, and H. Zhang, 2019: Strengthening tropical Pacific zonal sea surface temperature gradient consistent with rising greenhouse gases. Nat. Climate Change, 9, 517-522, https://doi.org/ 10.1038/s41558-019-0505-x.

Shepherd, T. G., 2016: A common framework for approaches to extreme event attribution. Curr. Climate Change Rep., 2, 28-38, https://doi.org/10.1007/s40641-016-0033-y.

__ and Coauthors, 2018: Storylines: An alternative approach to representing uncertainty in physical aspects of climate change. Climatic Change, 151, 555-571, https://doi.org/10.1007/s10584018-2317-9.

Sherwood, S. C., W. Ingram, Y. Tsushima, M. Satoh, M. Roberts, P. L. Vidale, and P. A. O'Gorman, 2010: Relative humidity changes in a warmer climate. J. Geophys. Res., 115, D09104, https://doi.org/10.1029/2009JD012585.

Sobel, A. H., S. J. Camargo, T. M. Hall, C.-Y. Lee, M. K. Tippett, and A. A. Wing, 2016: Human influence on tropical cyclone intensity. Science, 353, 242-246, https://doi.org/10.1126/ science.aaf6574.

Stansfield, A. M., K. A. Reed, and C. M. Zarzycki, 2020: Changes in precipitation from North Atlantic tropical cyclones under RCP scenarios in the variable-resolution Community Atmosphere Model. Geophys. Res. Lett., https://doi.org/10.1029/2019GRL086930, in press.

Stern, D., G. Bryan, and C.-Y. Lee, 2017: Using large eddy simulations to estimate the vulnerability of offshore wind farms to tropical cyclones. Sixth Int. Summit on Hurricanes and Climate Change: From Hazard to Impact, Heraklion, Greece, Amer. Meteor. Soc., 2.4, https://ams.confex.com/ams/97Annual/ webprogram/Paper315106.html.

Sugi, M., and J. Yoshimura, 2012: Decreasing trend of tropical cyclone frequency in 228-year high-resolution AGCM simulations. Geophys. Res. Lett., 39, L19805, https://doi.org/ 10.1029/2012GL053360.

- H. Murakami, and J. Yushimura, 2012: On the mechanism of tropical cyclone frequency changes due to global warming. J. Meteor. Soc. Japan, 90A, 397-408, https://doi.org/10.2151/ jmsj.2012-A24.

- - - and K. Yoshida, 2017: Projection of future changes in the frequency of intense tropical cyclones. Climate Dyn., 49, 619-632, https://doi.org/10.1007/s00382-016-3361-7.

Taylor, K. E., R. J. Stouffer, and G. A. Meehl, 2012: An overview of CMIP5 and the experiment design. Bull. Amer. Meteor. Soc., 93, 485-498, https://doi.org/10.1175/BAMS-D-11-00094.1.

Ting, M., S. J. Camargo, C. Li, and Y. Kushnir, 2015: Natural and forced North Atlantic hurricane potential intensity change in CMIP5 models. J. Climate, 28, 3926-3942, https://doi.org/ 10.1175/JCLI-D-14-00520.1.

Tippett, M., S. J. Camargo, and A. H. Sobel, 2011: A Poisson regression index for tropical cyclone genesis and the role of large-scale vorticity in genesis. J. Climate, 24, 2335-2357, https://doi.org/10.1175/2010JCLI3811.1.

Tory, K. J., S. S. Chand, J. L. McBride, H. Ye, and R. A. Dare, 2013: Projected changes in late-twenty-first-century tropical cyclone frequency in 13 coupled climate models from phase 5 of the Coupled Model Intercomparison Project. J. Climate, 26, 99469959, https://doi.org/10.1175/JCLI-D-13-00010.1.

Vecchi, G. A., and B. J. Soden, 2007: Global warming and the weakening of the tropical circulation. J. Climate, 20, 43164340, https://doi.org/10.1175/JCLI4258.1.

, - - A. T. Wittenberg, I. M. Held, A. Leetmaa, and M. J. Harrison, 2006: Weakening of tropical Pacific atmospheric circulation due to anthropogenic forcing. Nature, 441, 73-76, https://doi.org/10.1038/nature04744.

—_, A. Clement, and B. J. Soden, 2008: Examining the tropical Pacific's response to global warming. Eos, Trans. Amer. Geophys. Union, 89, 81-83, https://doi.org/10.1029/ 2008EO090002.

— doubling: Roles of atmospheric resolution, synoptic variability and background climate changes. Climate Dyn., 53, 59996033, https://doi.org/10.1007/s00382-019-04913-y.

Viale, F., and T. M. Merlis, 2017: Variations in tropical cyclone frequency response to solar and $\mathrm{CO}_{2}$ forcing in aquaplanet simulations. J. Adv. Model. Earth Syst., 9, 4-18, https://doi.org/ 10.1002/2016MS000785.

Walsh, K. J., and Coauthors, 2016: Tropical cyclones and climate change. Wiley Interdiscip. Rev.: Climate Change, 7, 65-89, https://doi.org/10.1002/WCC.371.

Wang, B., and J. C. L. Chan, 2002: How strong ENSO events affect tropical storm activity over the western North Pacific. J. Climate, 15, 1643-1658, https://doi.org/10.1175/1520-0442(2002) 015<1643:HSEEAT > 2.0.CO;2.

Watanabe, M., and Coauthors, 2010: Improved climate simulation by MIROC5: Mean states, variability, and climate sensitivity. J. Climate, 23, 6312-6335, https://doi.org/10.1175/ 2010JCLI3679.1.

Westervelt, D. M., L. W. Horowitz, V. Naik, J. C. Golaz, and D. L. Mauzerall, 2015: Radiative forcing and climate response to 
projected 21st century aerosol decreases. Atmos. Chem. Phys., 15, 12 681-12 703, https://doi.org/10.5194/acp-1512681-2015.

Woodruff, J. D., J. L. Irish, and S. J. Camargo, 2013: Coastal flooding by tropical cyclones and sea level rise. Nature, 504, 44-52, https://doi.org/10.1038/nature12855.

Wright, J. S., A. Sobel, and J. Galewsky, 2010: Diagnosis of zonal mean relative humidity changes in a warmer climate. J. Climate, 23, 4556-4569, https://doi.org/10.1175/2010JCLI3488.1.

Yokoi, S., Y. N. Takayabu, and H. Murakami, 2013: Attribution of projected future changes in tropical cyclone passage frequency over the western North Pacific. J. Climate, 26, 4096-4111, https://doi.org/10.1175/JCLI-D-12-00218.1.

Yoshida, K., M. Sugi, R. Mizuta, H. Murakami, and M. Ishii, 2017: Future changes in tropical cyclone activity in high-resolution large-ensemble simulations. Geophys. Res. Lett., 44, 99109917, https://doi.org/10.1002/2017GL075058.
Yu, J., Y. Wang, and K. Hamilton, 2010: Response of tropical cyclone potential intensity to a global warming scenario in the IPCC AR4 CGCMs. J. Climate, 23, 1354-1373, https://doi.org/ 10.1175/2009JCLI2843.1.

Yukimoto, S., and Coauthors, 2012: A new global climate model of the Meteorological Research Institute: MRI-CGCM3-Model description and basic performance. J. Meteor. Soc. Japan, $\mathbf{9 0 A}$, 23-64, https://doi.org/10.2151/jmsj.2012-A02.

Zanchettin, D., C. Timmreck, H.-F. Graf, A. Rubino, S. Lorenz, K. Lohmann, K. Krüger, and J. H. Jungclaus, 2012: Bi-decadal variability excited in the coupled ocean-atmosphere system by strong tropical volcanic eruptions. Climate Dyn., 39, 419-444, https://doi.org/10.1007/s00382-011-1167-1.

Zhao, M., I. M. Held, S.-J. Lin, and G. A. Vecchi, 2009: Simulations of global hurricane climatology, interannual variability, and response to global warming using a $50-\mathrm{km}$ resolution GCM J. Climate, 22, 6653-6678, https://doi.org/10.1175/2009JCLI3049.1. 